NUREG/CR- -5594

TI91 000760

\title{
Radiation Degradation in EPICOR-II Ion Exchange Resins
}

Manuscript Completed: August 1990

Date Published: September 1990

Prepared by

J. W. McConnell, Jr., D. A. Johnson, R. D. Sanders, Sr.

Idaho National Engineering Laboratory

Managed by the U.S. Department of Energy

EG\&G Idaho, Inc.

P.O. Box 1625

Idaho Falls, ID 83415

\author{
Prepared for \\ Division of Engineering \\ Office of Nuclear Regulatory Research \\ U.S. Nuclear Regulatory Commission \\ Washington, DC 20555 \\ NRC FIN A6876 \\ Under DOE Contract No. DE-AC07-76ID01570
}

\section{DISCLAIMER}

This report was prepared as an account of work sponsored by an agency of the United States Government. Neither the United States Government nor any agency thereof, nor any of their bility for the accuracy, completeness or implied, or assumes any legal liability or responsiprocess disclos or ans information, apparatus, product, or ence herein to any specific come that its use would not infringe privately owned rights. Refermanufacturer, or otherwise does necial product, process, or service by trade name, trademark, mendation, or avoring does not necessarily constitute or imply its endorsement, recom. and opinions of authors expressed heren Government or any agency thereof. The views United States Government or any agency thereof necessarily state or reflect those of the 


\section{PREVIOUS REPORTS IN SERIES}

NUREG/CR-4150, "EPICOR-II Resin Degradation-Results from First Resin Samples of Pr-8 and PF-20," EG\&G Idaho, Inc., July 1985.

NUREG/CR-4608, "EPICOR-II Resin Degradation-Results from Second Resin Samples of FF-8 and PF-20," EG\&G Idaho, Inc., October 1986. 


\begin{abstract}
The Low-Level Waste Data Base Development-EPICOR-II Resin/Liner Investigation Program funded by the U.S. Nuclear Regulatory Commission is investigating chemical and physical conditions for organic ion exchange resins contained in several EPICOR-II prefilters. Those prefilters were used during cleanup of contaminated water from the Three Mile Island Nuclear Power Station after the March 1979 accident. The work was performed by EG\&G Idaho, Inc. at the Idaho Engineering Laboratory. This is the final report of this task and summarizes results and analyses of three samplings of ion exchange resins from prefilters $\mathrm{PF}-8$ and -20 . Results are compared with baseline data from tests performed on unirradizted resins supplied by Epicor, Inc. to determine the extent of degradation due to the high intermal radiation dose received by the organic resins. Results also are compared with those of other researchers.
\end{abstract}

FIN No. A6876-Low-Level Waste Data Base DevelopmentEPICOR-II Resin/Liner Investigation.

iii/iv 


\section{SUMMARY}

The March 28, 1979 a cident at Three Mile Island Unit 2 released approximately 560,000 gal of contaminated water to the Auxiliary and Fuel Handling Buildings. The water was decontaminated using a three-stage demineralization system called EPICORII, containing organic and inorganic ion exchange media. The first stage was designated the prefilter, and the second and third stages were called demineralizers. Fifty EPICOR--II prefilters with high concentrations of radionuclides were transported to the Idaho National Engineering Laboratory (INEL) for interim storage before final disposal at the commercial disposal facility in the State of Washington. During the interim storage period at INEL, research was conducted on materials from those EPICOR-II prefilters. This study addresses the condition of the organic ion exchange resins in those prefilters.

Resin cores were obtained from prefilters $\mathrm{PF}-8$ and -20 during a first, second, and third sampling using special tools developed for that purpose. Removal of samples from the coring tools and preparation of those samples are discussed. A' series of characterization tests were performed on the resins to determine if degradation due to radiation had occurred during interim storage. Those tests included American Society for Testing Materials (ASTM) procedures, infrared spectroscopy, gas chromatography, high performance liquid chromatography, scanning electron microscopy, supercritical fluids chromatograph, barium chloride precipitation, inductively coupled plasma - atomic emission spectroscopy, and gamma-ray spectroscopy. Details of test methodologies and results are described.

Analysis comparing test results of the first, second, and third samplings of resins from EPICOR-II prefilters PF-8 and -20 and unirradiated resins obtained from Epicor, Inc., show that resin degradation is continuing in the EPICOR-II resins examined. The mechanism of degradation in those EPICOR-II prefilters is compared with earlier work and found to be consistent with those findings. The strong acid cation resins (divinylbenzene, polystyrene based structure) are losing effective cross-linking and functional groups, as well as experiencing a decrease in total exchange capacity as the absorbed radiation dose increases. The phenolic cation resins (phenol-formaldehyde based structure) show a loss of effective cross-linking and oxidation of the polymer chain. The analysis of the resins from the third sampling identify that very significant degradation has occurred.

While the organic ion exchange media (resins) from these EPICOR-II prefilters have suffered significant physical changes, it is shown that the contained radionuclides remain within the resin bed. The accentability of EPICOR-II prefilters for disposal in high integrity containers at a commercial disposal site is confirmed. 


\section{CONTENTS}

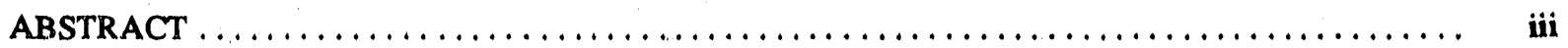

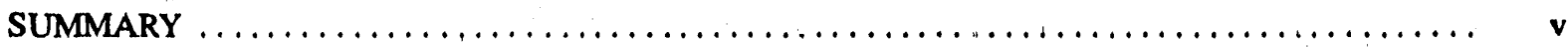

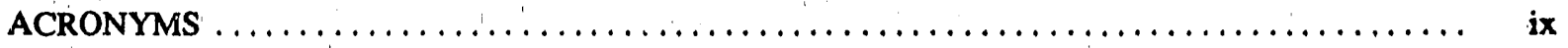

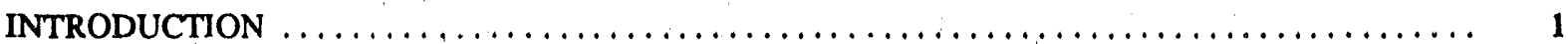

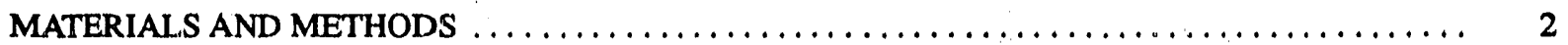

EPICOR-II Prefilters $\ldots \ldots \ldots \ldots \ldots \ldots \ldots \ldots \ldots \ldots \ldots \ldots \ldots \ldots \ldots \ldots \ldots \ldots \ldots, 2$

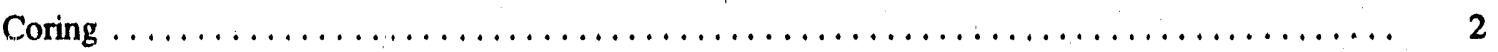

Measuring Radiation Doses in the Resin Beds $\ldots \ldots \ldots \ldots \ldots \ldots \ldots \ldots \ldots \ldots \ldots \ldots$

Gamma-Scanning of Resin Cores $\ldots \ldots \ldots \ldots \ldots \ldots \ldots \ldots \ldots \ldots \ldots \ldots \ldots, \ldots$

Sampling $\ldots \ldots \ldots \ldots \ldots \ldots \ldots \ldots \ldots \ldots \ldots \ldots \ldots \ldots \ldots \ldots \ldots \ldots \ldots \ldots \ldots \ldots \ldots, 6$

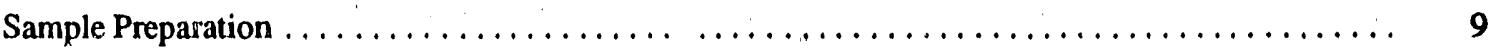

Characterization of Unirradiated and Irradiated Resins $\ldots \ldots \ldots \ldots \ldots \ldots \ldots \ldots \ldots \ldots \ldots$

ASTM Tests $\ldots \ldots \ldots \ldots \ldots \ldots \ldots \ldots \ldots \ldots \ldots \ldots \ldots \ldots \ldots \ldots \ldots \ldots \ldots, \quad 11$

Infrared Spectroscopy $\ldots \ldots \ldots \ldots \ldots \ldots \ldots \ldots \ldots \ldots \ldots \ldots \ldots \ldots \ldots \ldots \ldots, \quad 12$

Gas Chromatography $\ldots \ldots \ldots \ldots \ldots \ldots \ldots \ldots \ldots \ldots \ldots \ldots \ldots \ldots \ldots, 13$

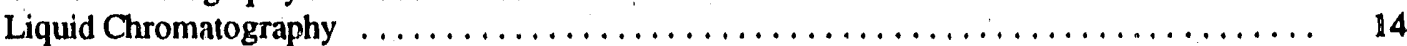

Supercritical Fluid Chromatograph $\ldots \ldots \ldots \ldots \ldots \ldots \ldots \ldots \ldots \ldots \ldots \ldots \ldots \ldots \ldots, 14$

Barium Chloride Precipitation for Detennination Sulfonic Acid Groups .............. 14

Inductive Coupled Plasma-Atomic Emission Spectroscopy for the Determination

of Sulfur (ICP-AES) $\ldots \ldots \ldots \ldots \ldots \ldots \ldots \ldots \ldots \ldots \ldots \ldots \ldots \ldots \ldots, 14$

Scanning Electron Microscopy $\ldots \ldots \ldots \ldots \ldots \ldots \ldots \ldots \ldots \ldots \ldots \ldots \ldots, 14$

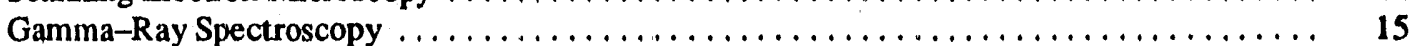

RESULTS AND INTERPRETATION $\ldots \ldots \ldots \ldots \ldots \ldots \ldots \ldots \ldots \ldots \ldots \ldots \ldots \ldots \ldots \ldots \ldots, 16$

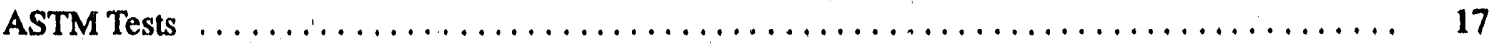

Infrared Spectroscopy $\ldots \ldots \ldots \ldots \ldots \ldots \ldots \ldots \ldots \ldots \ldots \ldots \ldots \ldots \ldots \ldots \ldots \ldots \ldots \ldots \ldots \ldots \ldots, 22$

Gas, Liquid, and Supercritical Fluids Chromatography $\ldots \ldots \ldots \ldots \ldots \ldots \ldots \ldots \ldots \ldots$

Determination of Sulfate $\ldots \ldots \ldots \ldots \ldots \ldots, \ldots \ldots \ldots, \ldots, \ldots \ldots \ldots \ldots, 22$

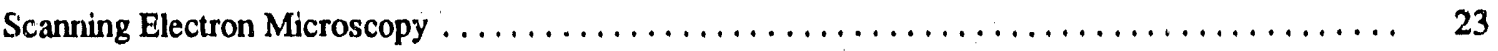

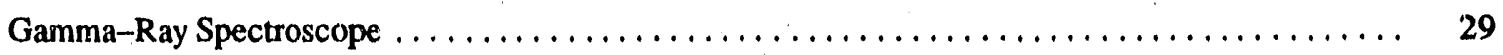

Physical Observations . . . . . . . . . . . . . . . . . . . . . . . . . . . . . . . . . . . 29 


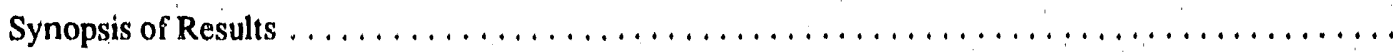

DISCUSSION AND CONCLUSIONS $\ldots \ldots \ldots \ldots \ldots \ldots \ldots \ldots \ldots \ldots \ldots \ldots \ldots \ldots \ldots, \quad 32$

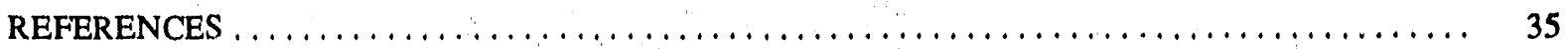

\section{FIGURES}

1. Schematic (isometric and full section ) of an EPICOR-II prefilter $\ldots \ldots \ldots \ldots \ldots \ldots \ldots \ldots \ldots$

2. Results of full-depth gross gamma measurements taken inside the hole created in the resin bed by the coring of EPICOR-II prefilter PF-8 during second sampling $\ldots \ldots \ldots \ldots \ldots \ldots \ldots$

3. Results of full-depth gross gamma measurements taken inside the hole created in the resin bed by the coring of EPICOR-II prefilter PF-20 during second sampling $\ldots \ldots \ldots \ldots \ldots \ldots \ldots$

4. Results of isotopic spectral measurements of the resin cure from EPICOR-II prefilter PF-20 during second sampling at an elevation of $29.25 \mathrm{in}$. (location of highest radioactivity) $\ldots \ldots \ldots \ldots$.

5. Isotopic (Cs-137) gamma-scan over the length of the resin core from EPICOR-II prefilter $\mathrm{PF}-8$, showing locations where the resin samples were removed

6. Isotopic (Cs-137) gamma-scan over the length of the resin core from EPICOR-Il prefilter $\mathrm{PF}-20$, showing locations where the resin samples were removed $\ldots \ldots \ldots \ldots \ldots \ldots \ldots \ldots$

7. Photograph of resin cores with shutters removed from EPICOR-II prefilters PF-20, (upper sample) and PF-8 (lower sample) $\ldots \ldots \ldots \ldots \ldots \ldots \ldots \ldots \ldots \ldots \ldots \ldots, \quad 8$

8. Schematic of apparatus used to collect resin samples from the coring tools $\ldots \ldots \ldots \ldots \ldots \ldots \ldots, 9$

9. Schematic of apparatus used to elute radionuclides from theresin samples $\ldots \ldots \ldots \ldots \ldots \ldots \ldots, 10$

10. Schematic of standard ASTM apparatus used for pretreatment of resins and backwashed and

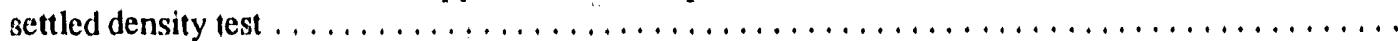

11. Schematic of standard ASTM apparatus for determining salt splitting and total exchange

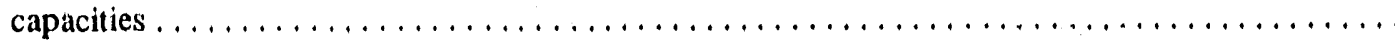

12. Change in total exchange capacity with increase in radiation dose $\ldots \ldots \ldots \ldots \ldots \ldots \ldots \ldots \ldots, 21$

13. SEM photomicrograph of unirradiated Epicor, Inc. strong acid cation resin at 12 magnification .....

14. SEM photomicrograph of EPICOR-II strong acid cation resin sample PF-20 at

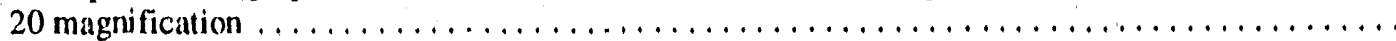

15. SEM photomicrograph of EPICOR-II strong acid cation resin sample PF-20, showing a

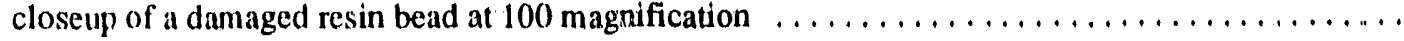

16. SEM photomicrograph of EPICOR-II strong acid cation resin sanple PF-8\#1 at 15 magnification, showing numerous damaged resin beads

17. SEM photomicrograph of EPICOR-II strong acid cation resin sample PF-8\#1 at 100 magnification, showing a typical resin bead fracture 
18. SEM photomicrograph of EPICOR-1I strong acid cation resin sample PF-8\#1, showing a closeup of one unusually damaged bead at 100 magnification

19. SEM photomicrograph of EPICOR-II strong acid cation resin sample PF8\#3, at 15 magnification

20. SEM photomicrograph of EPICOR--Il strong acid cation resin sample PF8\#3 showing ore resin bead which appears to have softened and dimpled at 100 magnification

21. SEM photomicrograph of unirradiated Epicor, Inc, phenolic cation resin at 100 magnification ......

22. SEM photomicrograph of EPICOR-II phenolic cation resin sample PF8\#2 at 18 magnification .....

23. SEM photomicrograph of EPICOR-II phenolic cation resin sample PF8\#2, showing a closeup of one cracked resin particle at 50 magnification

\section{TABLES}

1. Calculated radiation doses to resins from EPICOR-Il prefilters PF 8 and $-20 \ldots \ldots \ldots \ldots \ldots$

2. Radioactivity of resin soak, rinse, and acid composite samples in first, second, and third samplings

3. Results of ASTM tests on irradiated and unirradiated ion exchange resins-third sampling

4. ASTM test parameter changes of PF-8 and -20 strong acid cation resins versus unirradiated Epicor, Inc., strong acid cation resin (first, second, and third samplings)

5. Sulfate determined in aqueous solutions from resirs by inductively coupled plasmatatomic emission spectroscopy - third sampling

6. Cesium measured in aqueous solution from resins-third sampling

7. Synopsis of results from analysis of EPICOR-II irradiated resin samples PF-8\#1, PF-13\#2, PF-8\#3, and PF-20 from the first, second, and third samplings 


\section{ACRONYMS}

$\begin{array}{llll}\text { ASTM } & \text { American Society of Testing Materials } & \text { INEL } & \text { Idaho National Engincering Laboratory } \\ \text { BCL } & \text { Battelle Columbus Laboratories } & \text { IR } & \text { Infrared spectroscopy } \\ \text { BNL } & \text { Brookhaven National Laboratory } & \text { NRC } & \text { Nuclear Regulatory Commission } \\ \text { DOE } & \text { Department of Energy } & \text { SEM } & \text { Scanning electron microscope } \\ \text { GC } & \text { Gas chromatography } & \text { SFC } & \text { Super critical fluid chromatograph } \\ \text { HPLC } & \text { High performance liquid chromatography } & & \\ \text { ICP-AES } & \begin{array}{l}\text { Inductively Coupled Plasmi-Atomic } \\ \text { Emission Spectroscopy for the Determi- }\end{array} & \text { TEC } & \text { Total exchange capacity } \\ \text { nation of Sulfur } & \text { TRA } & \text { Test Reactor Area }\end{array}$




\section{RADIATION DEGRADATION IN EPICOR-II ION EXCHANGE RESINS, FINAL REPORT}

\section{INTRODUCTION}

The March 28, 1979 accidert at Three Mile Island Unit 2 released approximately $560,000 \mathrm{gal}$ of contaminated wate to the Auxiliary and Fuel Handling Bulldings. That water was decontaminated using a demineralization system called EPICOR-II developed by Epicor, Inc. The contaminated water was cycled through three stages of organic and inorganic ion exchange media. The fiust stage of the system was designated the prefilter, and the second and third stages were called demineralizers. After the filtration process, the ion exchange media in $\mathbf{5 0}$ of the prefilters contained radionuclides in concentrations greater than those established for disposal of similar materials as low-level wastes. Those prefilters were transported to the Idaho National Engineering Laboratory (INEL) for interim storage before final disposal. A special overpack, or high-integrity container, was developed during that storage period for use in disposing of the prefilters.

During the interim storage period at INEL, continuing research was conducted by EG\&G Idaho, Inc., on materials from those EPICOR-II prefilters, under the EPICOR and Waste Research and Disposition Program funded by the U.S. Department of Energy (DOE). That work now is directed by the U.S. Nuclear Regulatory Commission (NRC) as part of the LowLevel Waste Data Base Development-EPICOR-II Resin/Liner Investigation Programi. Studies are being conducted on: (a) organic ion exchange resins from selected prefilters and (b) corrosion-resistant behavior of the phenolic-coated steel walls of the prefilter liners. The resins are being examined to measure degradation and tests are being perfonmed to characterize solidified ion exchange media. The degradation studies are directed to determining the acceptability of EPICOR-II prefilters for disposal in high integrity containers at the commercial disposal site at Hanford, Washington, by identifying; (a) degradation effects on the ion-exchange resins caused by contained radiation (b) and possible release of contained radionuclides from the ion exchange resins.

Degradation studies traditionally have been conducted using resins irradiated by external sources, such as a reactor core or Co- $60 .^{2}$ The gamma dose, provided by an external source, simulates a dose that would be received from radionuclides retained on the resin matrix by ion exchange sites. Modes of degradation do not differ between extemal and internal radiation; but Reference 2 states that internal radiation causes more extensive damage than extemal radiation, presumably from such sources as short-range, highenergy beta radiation. The organic resin of EPICOR-II prefilters had been contained in liners for approximately nine years and experienced intemal radiation doses above $10^{7} \mathrm{rad}$.

This report discusses the resin degradation studies conducted on the third samples of organic ion exchange resins removed from the EPICOR-II prefilters (PF -8 and -20$)$ and compares results with findings from studies of the first and second sampling, as described in References 3 and 4. As part of the EPICOR and Waste Research and Disposition Program, 46 prefilters were disposed of at a commercial disposal facility. Four prefilters used in the NRC studies were stored in femporary storage casks outsicle the Hot Shop of Test Area North Building 607 (TAN-607) at the INEL. The third sampling will be the final examination of this study. The remaining four prefilters were disposed at the Radionctive Waste Management Complex, the INEL, disposal facility, 5,6 


\section{MATERIALS AND METHODS}

\section{EPICOR-II Prefilters}

EPICOR-II prefilter liners are 4-ft-diameter by 4-ft-high cylinders with $1 / 4-i n$.-thick bottoms (Figure 1). The liners are of welded construction using ASTM Type A-36 carbon steel. The internal and external surfaces are painted with Phenoline 386 coating. Each liner contains about $30 \mathrm{ft}$ of ion exchange media. Several types of media (i.e., cation, anion, mixed bed, and/or zeolite) were placed in each liner in layers. Of the prefilters received at INEL, 39 contained both organic ion exchange resins and inorganic zeolite; 11 contained organic resins only. During the filtration process, a perforated, four-branch influent manifold distributed contaminated water over the ion exchange media, while the effluent was drawn off from the bottom of the prefilter through a porous, multibranched return manifold. Both manifolds are piped to a manifold plate on top of the liner. A vent port and adaptors for liquid-level detectors also are located on the manifold plate. A manway is located beside the manifold plate on the top of the liner, through which ion exchange media were loaded into the liner. Removal of resins from the prefilter also was accomplished through that manway, using coring tools.

Throughout this report, the following nomenclature applies to various sizes and configurations of materials removed from EPICOR-II prefilters for examination:

- Resin Core--one core removed from each prefilter $P F-8$ and -20 , using coring tools

- Resin Samples-100-mL volumes of resin removed from the cores [three samples from PF-8 (designated PF-8\#1, PF-8\#2, and $\mathrm{PF}-8 \# 3$ ) and one from $\mathrm{PF}-20$ (designated PF-20)]

- Aliquots-small quantities obtained from the resin samples.

To develop baseline data for resin degradation studies, unirradiated ion exchange resins repre.sentative of those in the prefilters were obtained from Epicor, Inc. The unirradiated resins were identified by functional group, exchangeable species, and matrix (e.g., sulfonic acid, strong acid cation, and styrene). They were characterized for comparison with the resins from PF-8 and-20. Studies at Brookhaven

a. Trade name of the Carboline Company
National Laboratory in New York, confirmed that this comparative method was best suited to the analysis of the EPICOR-Il ion exchange materials (Reference 7). Both the irradiated and unirradiated resins were examined using similar techniques. The resins were pretreated so as to put the resins in a standard form for comparison purposes. Then, ASTM tests were used to determine exchange capacity, density, and moisture content. ${ }^{8}$ Infrared spectroscopy (IR) was used to identify functional groups (e.g., sulfonic acid, phenolic, and quatemary ammonium) and matrix material (styrene and phenol), Vapor phase chromatograph was used to analyze the rinse, soak, and acid rinse solutions from the ASTM tests qualitatively for styrene, divinylbenzene, or other soluble organic specie's. High-performance liquid chromatography was used to look for other possible soluble organic products. The third sampling included super-critical fluid chromatography, which should allow the detection of macro molecules (fragments of the resin polymer). Inductive coupled plasma-atomic emission spectroscopy was used for determining sulfonic acid groups and scanning electron microscopy for determining the physical condition of the resins. Gammaray spectroscopy was used to determine radionuclides in aqueous solutions from the third sampling.

\section{Coring}

Kesin cores were removed remotely from prefilters PF. 8 and -20 during the third coring in 1989, using coring equipment based on a design developed at Battelle Columbus Laboratories (BCL) and modified for use at the INEL. ${ }^{9}$ PF -8 (containing organic resins) and $\mathrm{PF}-20$ (containing organic resins and zeolite) were selected for the resin degradation studies hecause they are highly loaded representatives $(1,400$ and $2,000 \mathrm{Cr}$, respectively) of the two types of EPICOR-II prefilters. Water was added to the top of the prefilter beds during coring to provide lubrication for the coring tools, which would not enter the beds more than a few inches without it. Between 25 and 50 gal of water were added to each bed during coring operations. The coring equipment was described in Reference 3.

The resin core contained layers of ion exchange media in the same relative positions as in the prefilter bed. The void in the coring tool above the upper level of the resin was filled with unirradiated zeolite before lowering the tool to the horizontal position. The zeolite filler prevented shifting of the resin during transport. The coring tools were placed horizontally in separate casks 


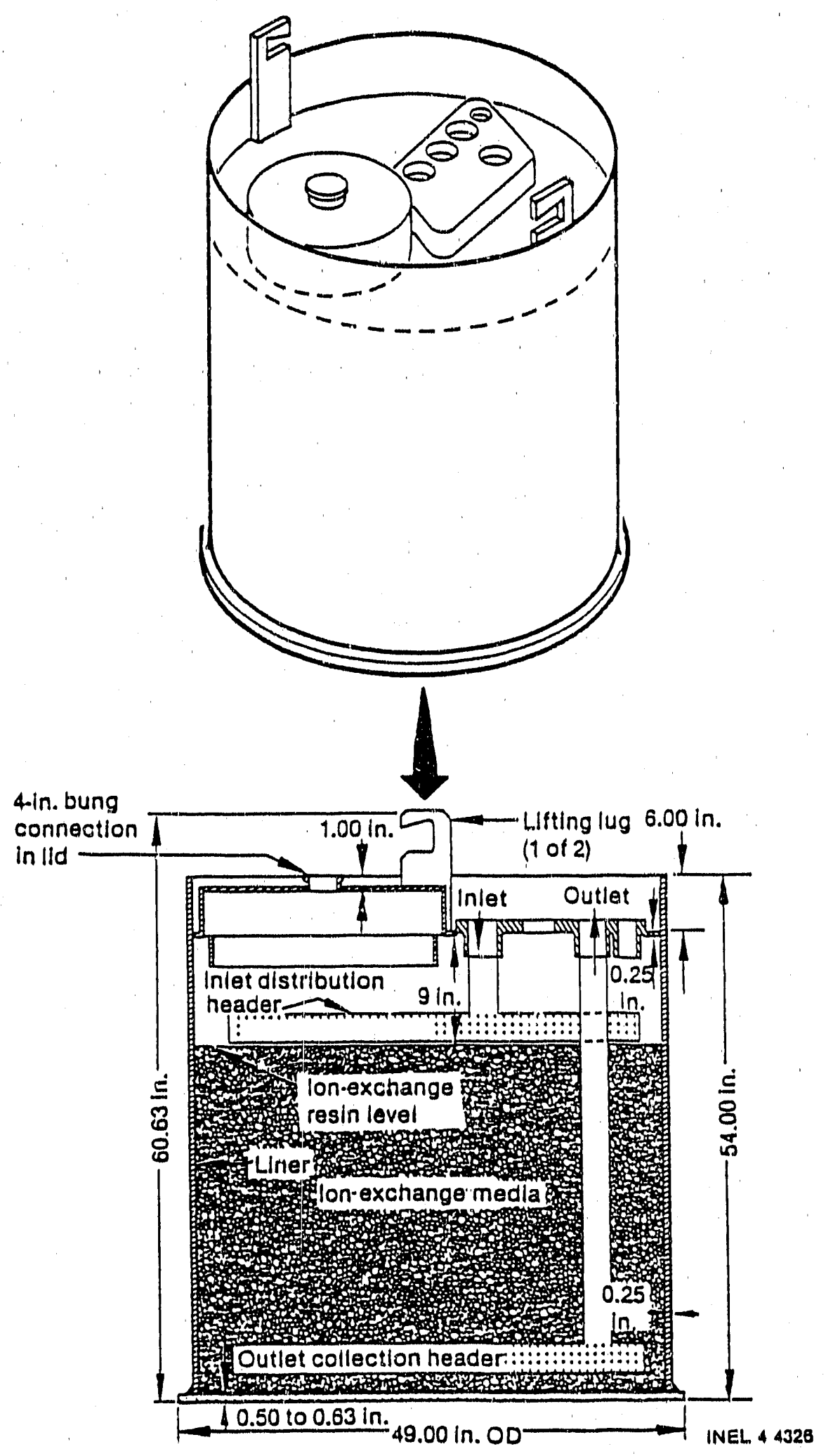

Figure 1. Schematic (isometric and full section) of an EPICOR-II prefilter. 
and transported from the TAN-607 Hot Shop to " hot cell at the Test Reactor Area (TRA) for gammascanning arid removal of resin samples.

\section{Measuring Radiation Doses in the Resin Beds}

Full-depth gross gamma scans were made in the pretilter resin beds after removing cores during each of the three samplings. Those scans were used to estimate the fotal integrated radiation dose absorbed by the resins. Measurements were made with a Victoreen Model 510 roentgen rate meter, which used an air-oquivalent ionization chamber radiation detector (Model 607) and associated current measuring electrometer. The task was accomplished by remotely lowering the radiation detector down the 2-by-3-in, holes created in the resin beds during the coring process. The averages of the actual gamma scan measurements made during insertion and retraction of the detector al each location during the second sampling are given in Figures 2 and 3. Radiation measurements made at the elevations of interest were used with the calculations ol maximum cumulative doses ${ }^{a}$ to estimate the total integrated beta dose. The calculated beta dose and the measured ganma dose for each resin sumple location are listed in Tuble 1. As would be expected, the total doses are increasing with time. These final total doses have been adjusted from previous values upon inclusion of the information obtained during the third sampling. There has been no appreciable shift in these curves toward the bottom of the bed which indicates little or no movement of radionuclides through the beds.

\section{Gamma-Scanning of Resin Cores}

The full-length resin cores from PF-8 and -20 first and second samplings were scanned in the coring tool using a $\mathrm{Ge}(\mathrm{Li})$ gamma-ray detector (with associated electronics and a $0.5-$ it,- wide by 1,0-in,-high colli. mator) to determine axial gross gamma activity versus

a. D. E. Martz, Calculated Cumulative Radiation Doses to EPICOR Prefilter Resins, private communication, EG\&G Idaho, Inc., April 1985.

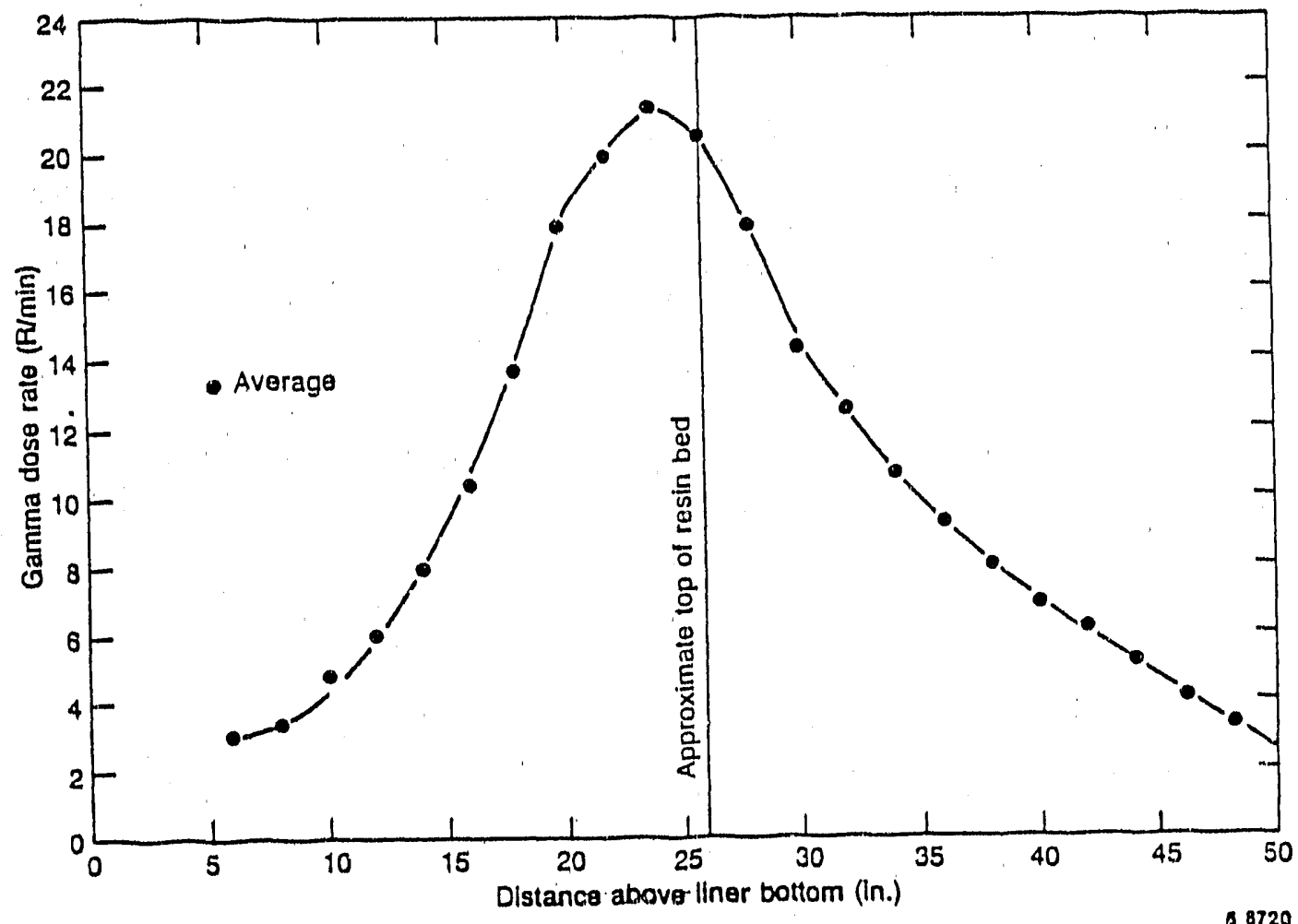

Figure 2. Results of full-depth gross gamma measurements taken inside the hole created in the resin ired by the coring of EPICOR-II prefilter PF-8 during second sampling. 


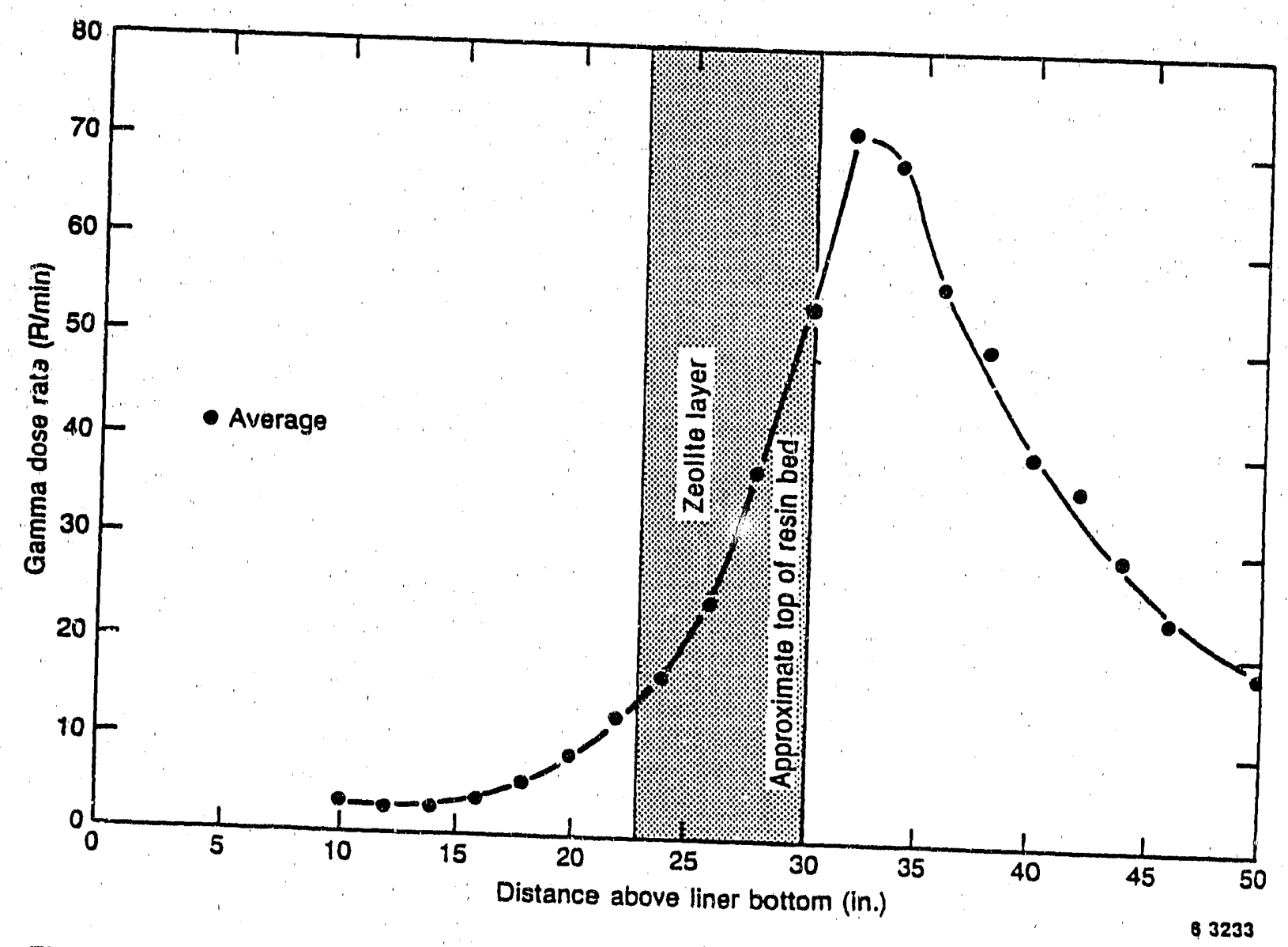

Figure 3. Recults of full-ilepth gross gamma measurements taken inside the hole created in the resin bed by the
coring of EPICOR-II prefilter PF- 20 during second sampling

Table 1. Calculated radiation doses to resins from EPICOR-II prefilters PF-8 and -20

\begin{tabular}{|c|c|c|c|c|c|c|}
\hline Sample & $\begin{array}{c}\text { Date Prefilter } \\
\text { Removed } \\
\text { from Service } \\
\text { at TMI-2 } \\
\end{array}$ & $\begin{array}{c}\begin{array}{c}\text { Date Resin } \\
\text { Cored }\end{array} \\
\end{array}$ & $\begin{array}{c}\text { Measured Activity } \\
\text { at Location of } \\
\text { Sample in Prefilter } \\
\text { (R/min) } \\
\end{array}$ & $\begin{array}{l}\text { Total Gamma } \\
\text { Radiation Dose } \\
\text { (rad) } \\
\end{array}$ & $\begin{array}{c}\text { Total Beta } \\
\text { Radiation Dose } \\
(\mathrm{rad}) \\
\end{array}$ & $\begin{array}{c}\text { Total } \\
\text { Radiation Dose } \\
(\mathrm{rad}) \\
\end{array}$ \\
\hline $\begin{array}{l}\text { PF-8\#1 } \\
\text { PF-8\#2 } \\
\text { PF-20 }\end{array}$ & $\begin{array}{l}18 \operatorname{Dec} 79 \\
18 \text { Dec } 79 \\
13 \text { March } 80\end{array}$ & $\begin{array}{l}4 \text { Oct } 83 \\
4 \text { Oct } 83 \\
11 \text { Oct } 83\end{array}$ & $\begin{array}{l}23.7 \\
15.4 \\
20.0\end{array}$ & $\begin{array}{l}4.7 \times 10^{7} \\
3.1 \times 10^{7} \\
3.8 \times 10^{7}\end{array}$ & $\begin{array}{l}1.8 \times 10^{7} \\
1.2 \times 10^{7} \\
1.3 \times 10^{7}\end{array}$ & $\begin{array}{l}6.6 \times 10^{7} \\
4.3 \times 10^{7} \\
5.1 \times 10^{7}\end{array}$ \\
\hline $\begin{array}{l}P F-8 \# 1 \\
P F-8 \# 2 \\
P F-8 \# 3 \\
P F-20\end{array}$ & $\begin{array}{l}18 \operatorname{Dec} 79 \\
18 \operatorname{Dec} 79 \\
18 \text { Dec } 79 \\
13 \text { March } 80\end{array}$ & $\begin{array}{l}10 \text { Oct } 85 \\
10 \text { Oct } 85 \\
10 \text { Oct } 85 \\
14 \text { Oct } 85\end{array}$ & $\begin{array}{l}21.4 \\
15.2 \\
20.3 \\
14.0\end{array}$ & $\begin{array}{l}6.5 \times 10^{7} \\
4.6 \times 10^{7} \\
6.3 \times 10^{7} \\
4.9 \times 10^{7}\end{array}$ & $\begin{array}{l}2.5 \times 10^{7} \\
1.8 \times 10^{7} \\
2.4 \times 10^{7} \\
1.7 \times 10^{7}\end{array}$ & $\begin{array}{l}9.0 \times 10^{7} \\
6.4 \times 10^{7} \\
8.8 \times 10^{7} \\
6.6 \times 10^{7}\end{array}$ \\
\hline $\begin{array}{l}P F-8 \# 1 \\
P F-8 \# 2 \\
P F-8 \# 3 \\
P F-20\end{array}$ & $\begin{array}{l}18 \operatorname{Dec} 79 \\
18 \operatorname{Dec} 79 \\
18 \operatorname{Dec} 79 \\
13 \text { March } 80\end{array}$ & $\begin{array}{l}25 \text { May } 89 \\
25 \text { May } 89 \\
25 \text { May } 89 \\
21 \text { May } 89\end{array}$ & $\begin{array}{l}21.2^{\mathrm{a}} \\
13.5^{\mathrm{a}} \\
19.8^{\mathrm{a}} \\
13.2^{\mathrm{a}}\end{array}$ & $\begin{array}{r}10.5 \times 10^{7} \\
6.7 \times 10^{7} \\
9.8 \times 10^{7} \\
6.4 \times 10^{7}\end{array}$ & $\begin{array}{l}4.0 \times 10^{7} \\
2.6 \times 10^{7} \\
3.7 \times 10^{7} \\
2.3 \times 10^{7}\end{array}$ & $\begin{array}{r}14.5 \times 10^{7} \\
9.2 \times 10^{7} \\
13.5 \times 10^{7} \\
8.7 \times 10^{7}\end{array}$ \\
\hline
\end{tabular}

a. Calculated from first and second sampling data. 
length of the core. ${ }^{10}$ The axial locations of highest radionuclide activity for the resin cores were determined using those scans. Then, isotopic spectral measurements were made at the locations of highest activity during the first sampling from PF-20, as shown in Figure 4. There were two radionuclides having measurable concentrations detected by the gamma spectral scans, Cs-134 and Cs-137. It is noted that antimony has been found in these resins, but was not seen in the spectral scan (Figure 4) due to masking by facility back.ground count. Based on that information from the first sampling, isotopic gamma-ray intensities for Cs-134 and Cs-137 were measured as a function of distance along the resin cores. The results for $\mathrm{Cs}-137$ are shown in Figures 5 and 6 for PF- 8 and -20 respectively. The resin samples were collected from or near those regions of highest radionuclide loading. However, it is noted that the PF-20 sample was not collected from the region in the organic resin of highest radionuclide loading (near the bottom of the core), but rather the sample was removed from the resin adjacent to the zeolite. In that prefilter, the zeolite contained by far the highest concentration of radionuclides and thus produced an integrated dose much higher than that seen at the bottom of the resin core (see Figure 6). Because zeolites have not been used in routine ion exchange service at commercial nuclear power plants, the scope of this study has been limited
10 the degradation of organic ion exchange resins; therefore, only organic resin samples were removed from the cores.

\section{Sampling}

At TRA, each resin-filled coring tool was transferred from its cask into the hot cell for remote removal of resin samples. The shutter of the coring tool was withdrawn to expose the ion exchange media (resin). The cores of PF-8 and -20 with shutters removed are pictured in Figure 7. Composite figures of the cores showing ion exchange media layers were shown in Reference 3 and 4. It should be noted that some smearing of material from one layer into another occurred when each shutter was inserted and withdrawn. That smearing required careful removal of the mixed surface material to expose unmixed resin near the center of the core, for the unmixed material was the target for collection.

The resin samples were obtained from the cores, using a vacuum pump and partially water-filled graduated glass column (See Figure 8). One end of a flexible rubber tube was attached near the top of the glass column and the other end was connected to a vacuum pump outside the hot cell. A segment of

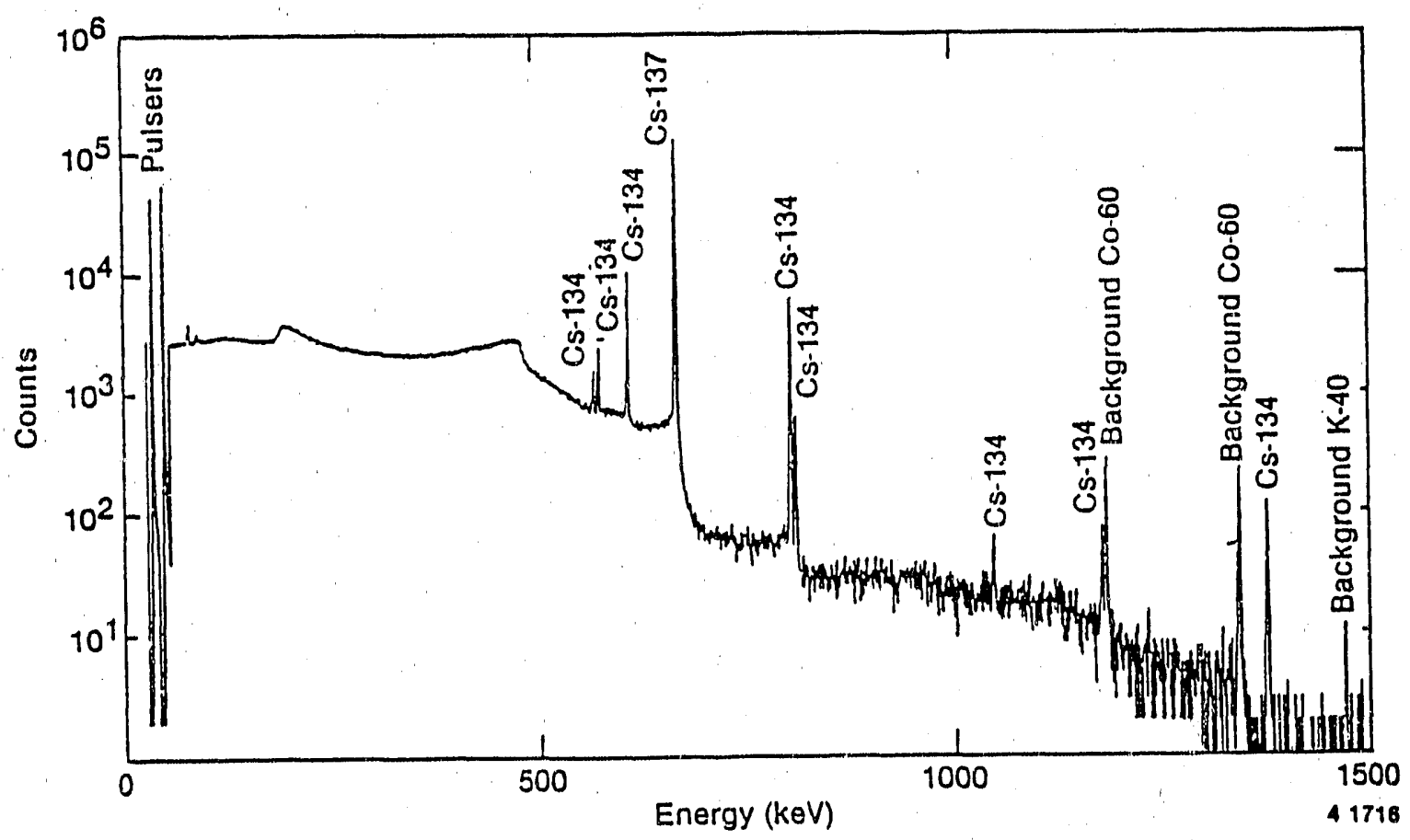

Figure 4. Results of isotopic spectral measurements of the resin core from EPICOR-Il prefilter PF-20 during first sampling at an elevation of 29.25 in. (location of highest radioactivity). 


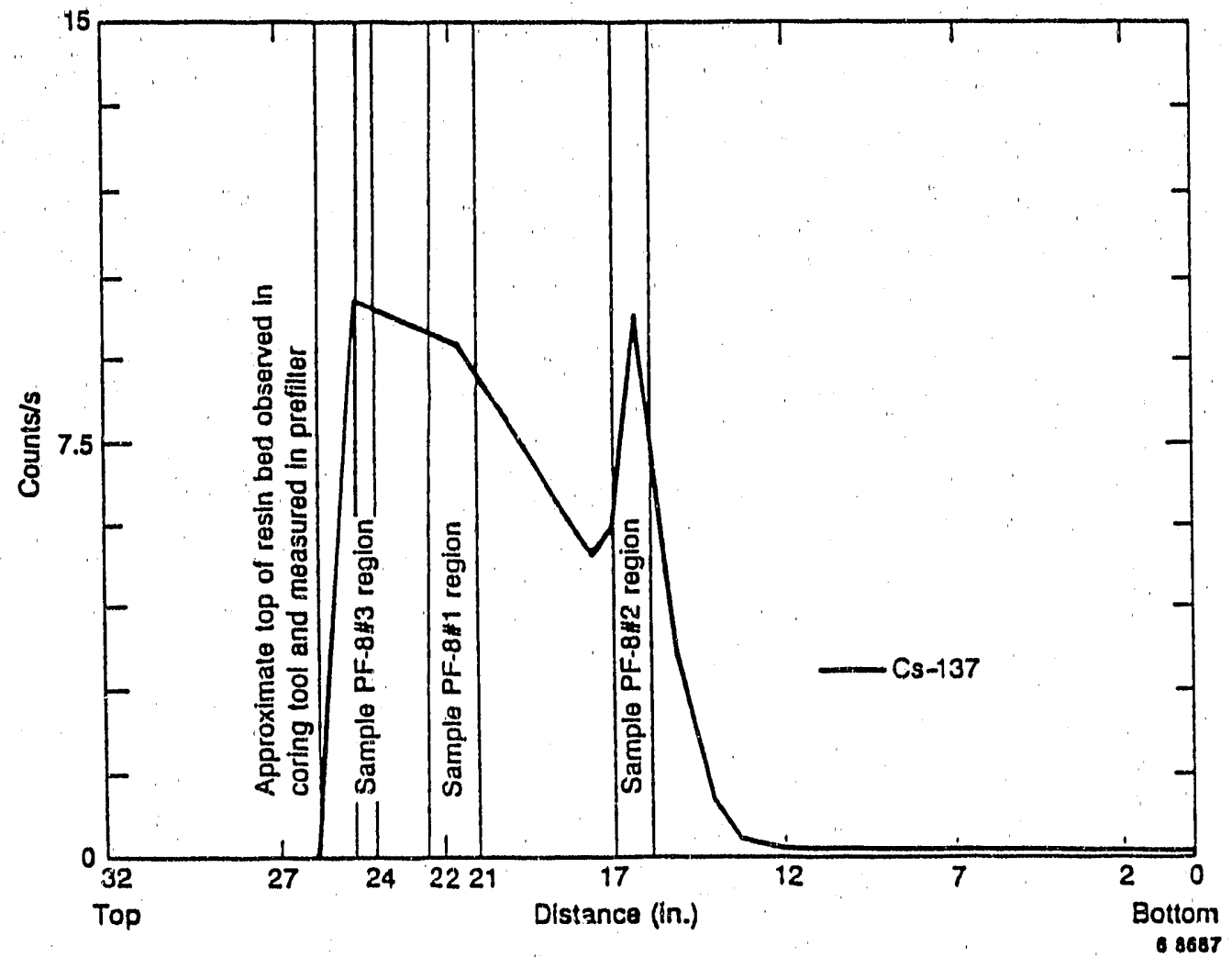

Figure 5. Isotopic (Cs-137) gamma-scan over the length of the resin core from EPICOR-II prefilter PF-8, showing locations where the resin samples were removed.

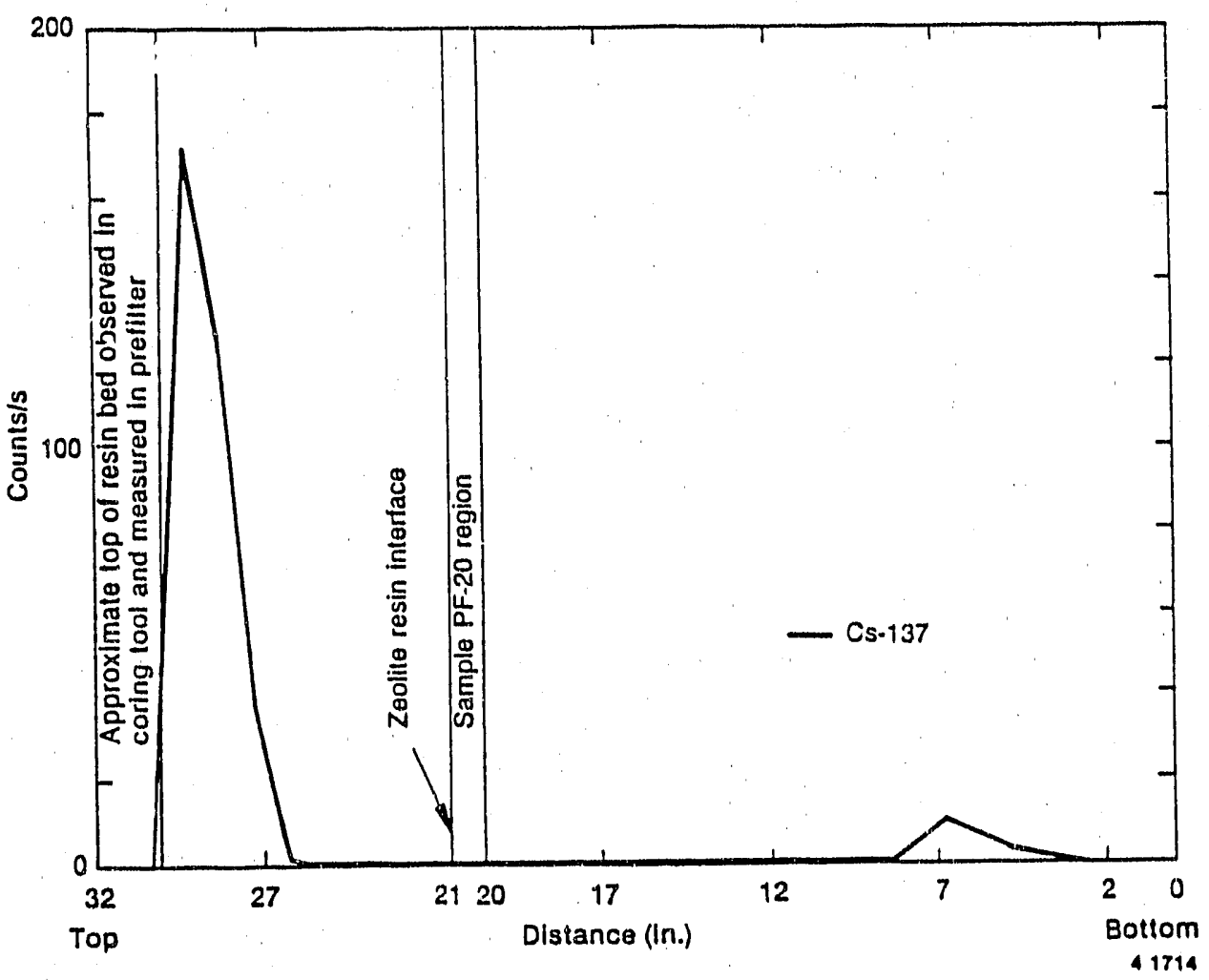

Figure 6. Isotopic (Cs-137) gamma-scan over the length of the resin core from EPICOR-II prefilter PF-20, showing locations where the resin samples were removed. 

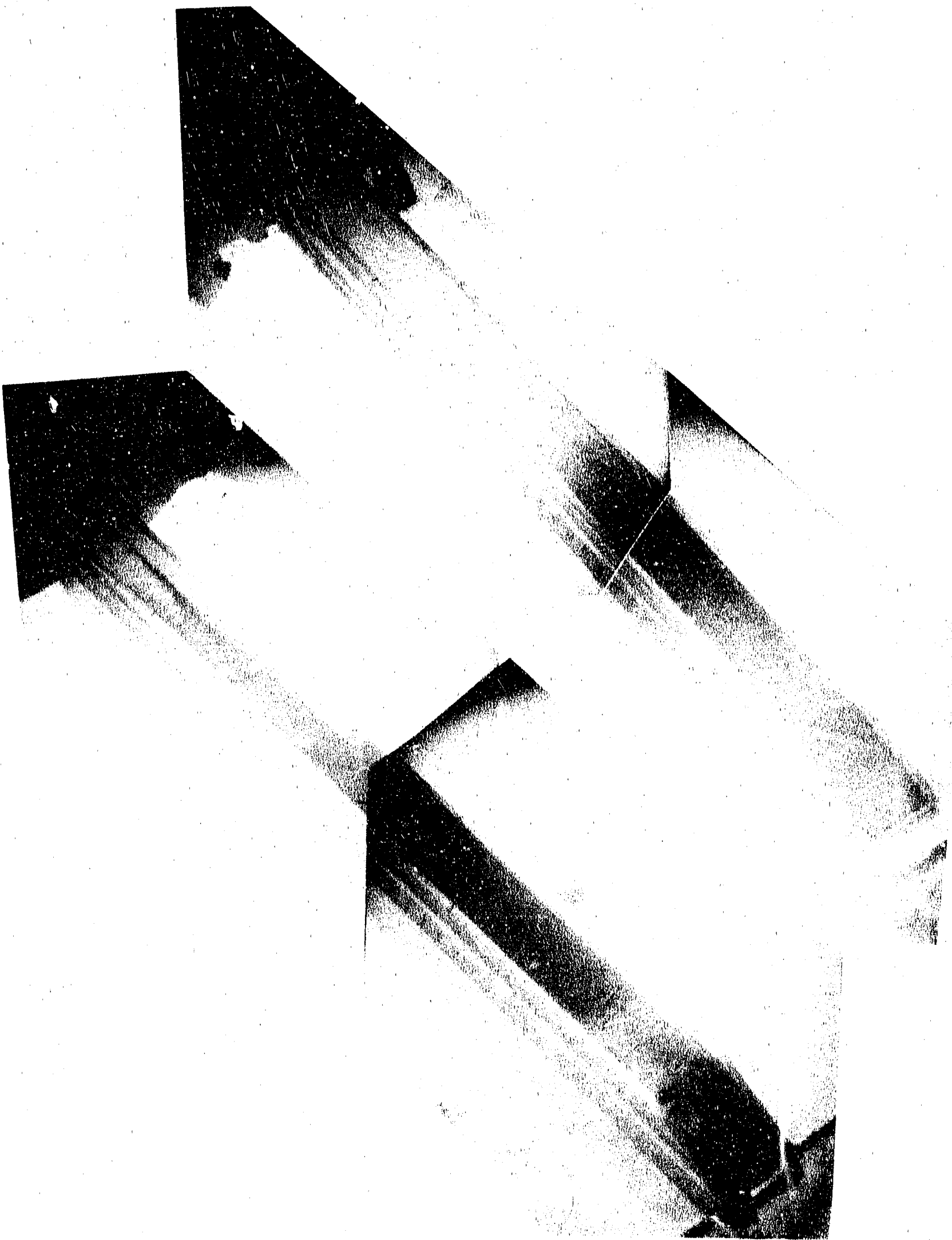

Figure 7. Photograph of resin cores with shutters removed from EPICOR-II pretilters PF-20 (upper sample) and PF-8 (lower sample). 


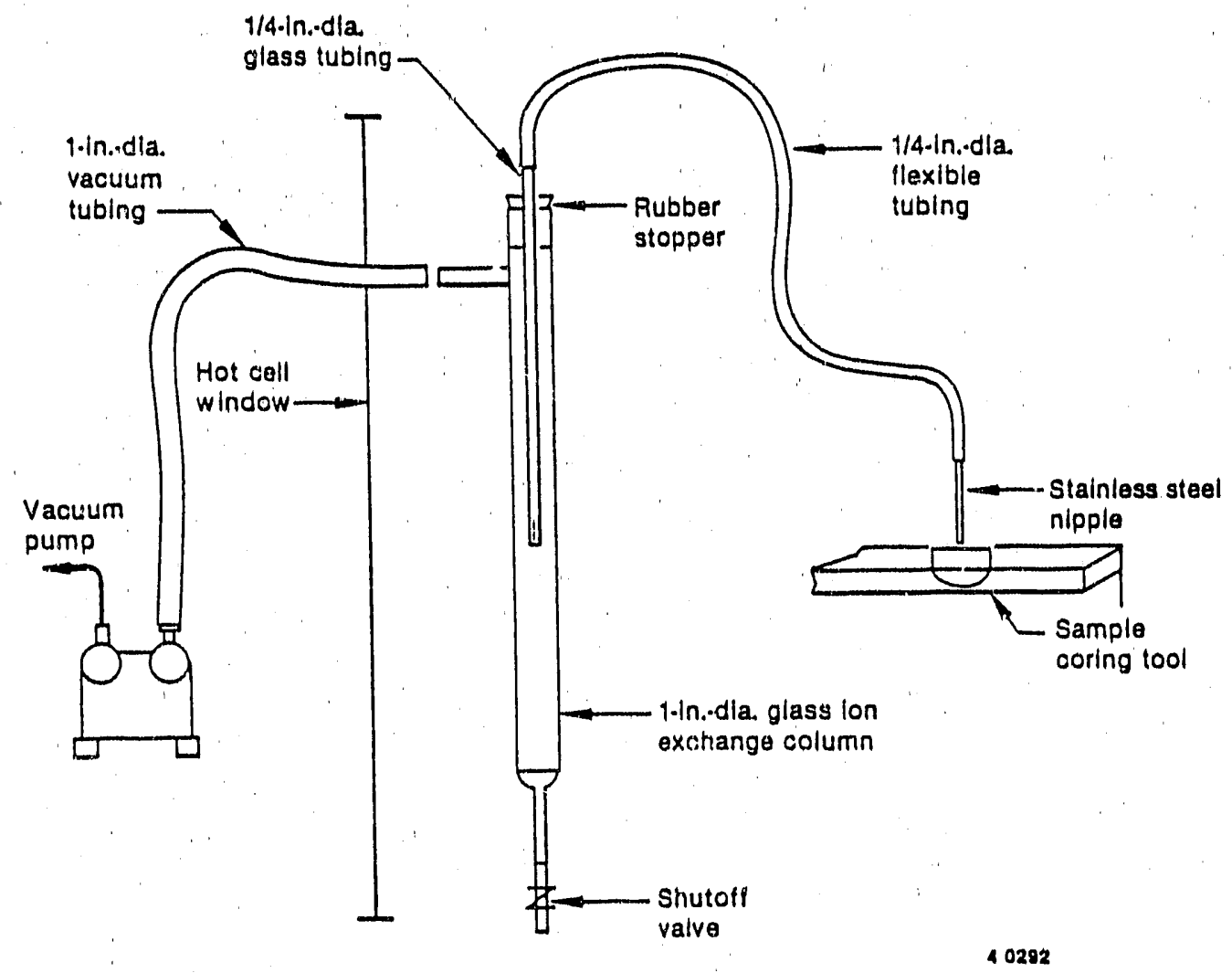

Figure 8. Schematic of apparatus used to collect resin samples from the coring tools.

rubber tubing was atrached from the top of the glass column to a stainless steel tube to form a wand (Figure 8). With the vacuum pump operating, the wand was positioned with a master-slave manipulator over the target resin in such a way that the resin was drawn into the wand, thence into the column. Sample sizes of $100 \mathrm{~mL}$ were collected. Three samples were collected from the PF-8 core, two styrene cation resin (PF-8\#1 and $\mathrm{PF}-8 \# 3)$ and one phenolic cation resin $(\mathrm{PF}-8 \# 2)$. A sample of styrene cation resin was collected from $P F-20$. No anion resin sample was collected from either core because of the lower radionuclide content of the anion exchange resin and the lower radiation dose as shown in Figures 2 and 3 (resulting in much less degradation than in the cation exchange resins).

\section{Sample Preparation}

The radiation levels in the PF-8 and -20 samples were of such intensity that work performed on those resins would have to have been done within a hot cell environment. That type of environment would have made the characterization and analysis of the resin samples very costly and time consuming. It had been shown by tests performed at INEL on unirradiated resins that an Epicor, Inc., resin could be stripped of $99 \%$ of its cations, using a $10 \%$ hydrochloric acid so- lution. ${ }^{\text {a }}$ Based on that information, the radionuclides (cations) were eluted from the PF- 8 and -20 resin samples. This technique is based on normal resin industry regeneration procedures and will not contribute to degradation of the ion exchange resins.

As described in the previous section, samples were removed from the coring tools, drawn into a 1 in.-dia. by 18 -in.-high ion exchange column containing $50 \mathrm{~mL}$ of deionized water (see Figure 8), and allowed to stand 24 hours in the water-filled column. Each ion exchange column then was reconfigured, as shown in Figure 9. The distilled water soak was removed through the shuroff valve at the bottom of the column and retained for gas, liquid and supercritical fluid chromatcgraphy analysis. The various chromatography techniques were used for determining the presence of soluble organic resin degradation products. The deionized water soak was analyzed for the presence of any functional group components, such as sulfonic acid, which had been dissociated from the resin. All resin samples were rinsed two times with deionized water, which was added by the pump through

a. R. D. Sanders, Bench Study of Batch Elution of Cation Resins, private communication, EG\&G Idaho, Inc. 


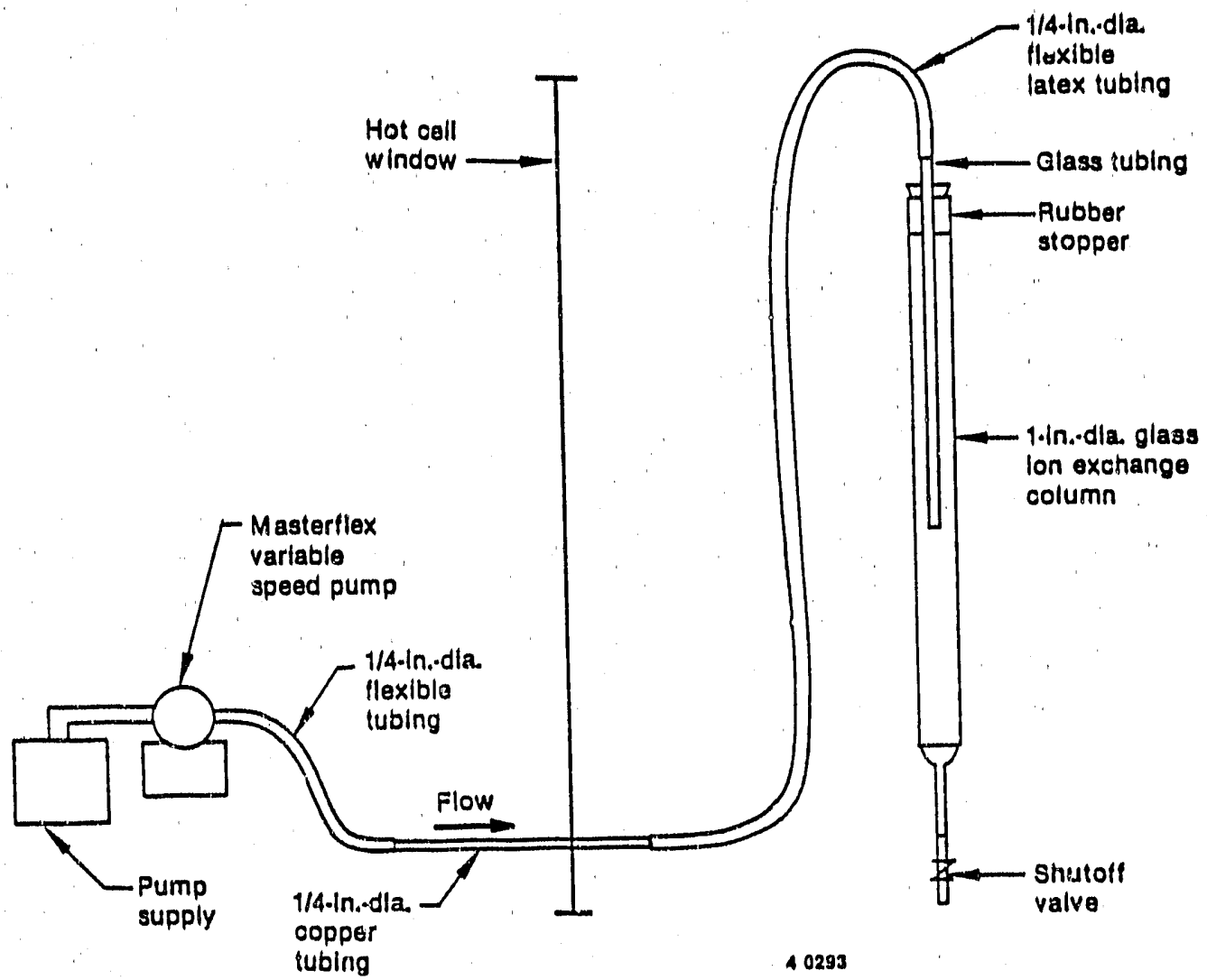

Figure 9. Schematic of apparatus used to elute radionuclides from the resin sample.

the tubing at the top of the column. It was very difficult to get any kind of reasonable flow through the columns containing samples PF-8\#1, PF-8\#3, and PF-20 so these three samples were rinsed out of the columns and rinsed with deionized water. The resulting solution was decanted off of the resin samples. The resins samples were then returned to their respective ion exchange columns. The decant solutions were saved for soluble organic and functional group analysis. The deionized water rinse also was saved for chromatography analysis and functional group tests.

A solution of $10 \%$ hydrochloric acid was pumped through each resin sample at a rate of $100 \mathrm{~mL} / \mathrm{min}$, using the configuration shown in Figure 9. That procedure continued until 60 sample volumes (the amount determined to remove $99 \%$ of the cations) or $6 \mathrm{~L}$ of acid were pumped through the resins. Representative quantizies of that acid rinse were collected for later chromatography and functional group analysis.

The deionized water soak, deionized water rinse, decant rinses, and hydrochloric acid inse reduced the radionuclide content of the resins and made it possible to remove the samples from the hot cell and perform the analyses in a Type Il fume hood equipped with a high-efficiency particulate air filter on the outlet duct.
Each of the liquid samples was monitored for radioactivity upon removal from the hot cell. Those measurements were used to maintain radiological control and also as an indication of resin degradation.

\section{Characterization of Unirradiated and Irradiated Resins}

Several analytical methods are needed to charac. terize a specific ion exchange resin. Those methods include the following:

- ASTM Procedures for the Physical and Chemical Properties of Particulate Ion Exchange Resins ${ }^{11}$

- Infrared spectroscopy (used in the first and second samplings)

- Gas chromatography

- Liquid chromatography

- Supercritical fluid chromatography (third sampling only)

- Barium chloride precipitation for determination of sulfonic acid groups (first and second sampling) 
- Inductively coupled plasma-atomic emission spectroscopy for the determination of sulfonic acid groups (third sampling)

- Ganma-ray spectroscopy (third sampling)

- Scanning electron microscopy.

The above analytical methods were used to characterize the samples from $\mathrm{PF}-8$ (strong acid cation and phenolic cation) and PF-20 (strong acid cation) and the unirradiated Epicor, Inc., resins (strong acid cation and phenolic cation).

ASTM Tests. ASTM procedures were used to deter. mine chernical and physical conditions of the ion exchange resins. Results from analysis of irradiated resins (from the first, second, and third samplings) were compared with results from unirradiated resins to determine if degradation. had occurred. Those results are presented in the "Results and Interpretation" section of this report. The following ASTM tests" were

a. The tests were preformed in accordance with the ASTM standards and deviations are within allowable limits of those standards. used for the strong acid cation and phenolic cation exchange resinis:

- Pretreatment (ASTM D2187-77 Method A)

- Water retention capacity (ASTM D2187-77 Method B)

- Backwashed and settled density (ASTM D2187-..77 Method C)

- Salt-splitting capacity (ASTM D2187-77 Method E)

- Total excharge capacity (ASTM D2187-77 Method F),

Pretreatment. The pretreatment phase of the A.STM procedure was used to convert ion exchange resins to one standard form (usually the sodium form for cation resins). The standard form provides a baseline from which the other ASTM tests can le performed. An ion exchange column apparatus (See Figure 10) was set up and the resin sample added to the

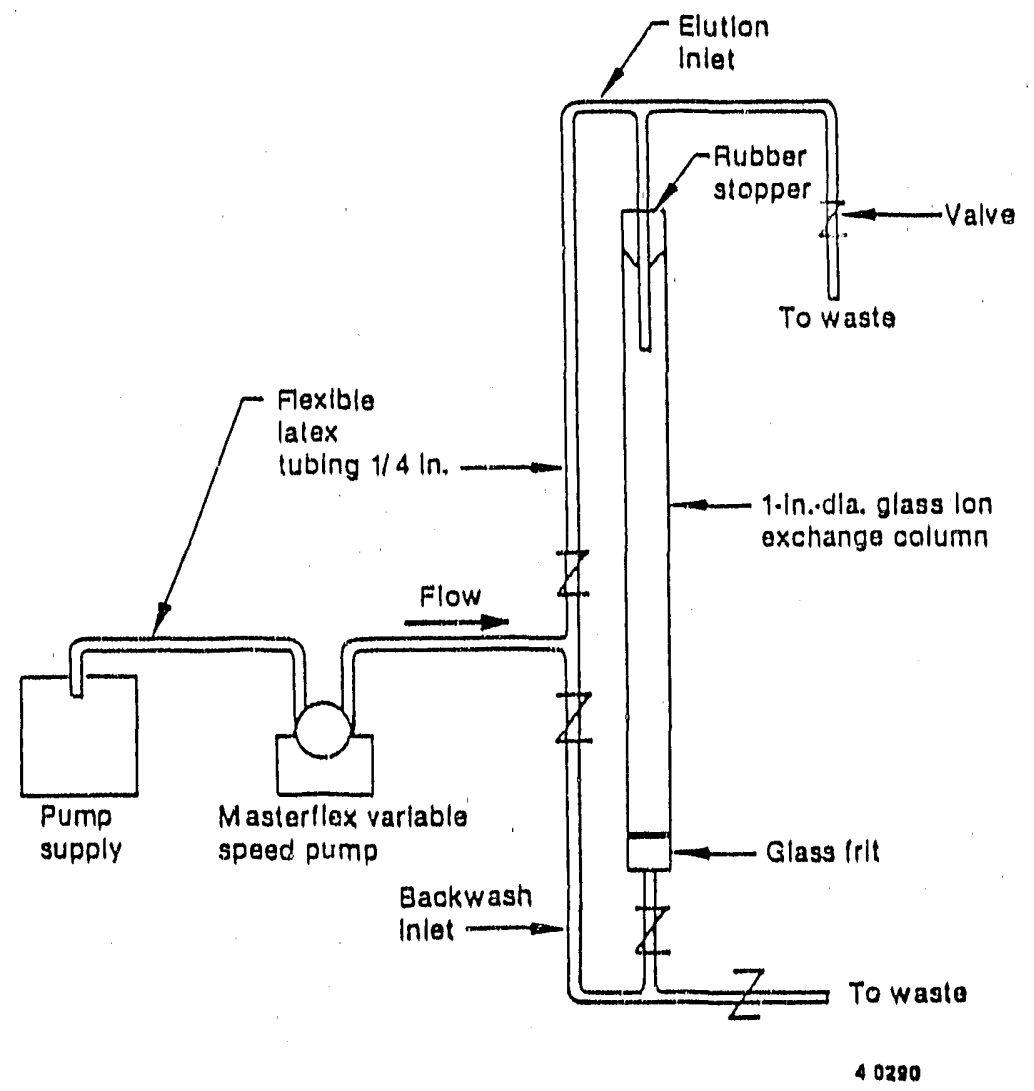

Figure 10. Schematic of standard ASTM apparatus used for pretreatment of resins and backwashed and settled density test. 
column. The resin was backwashed with deionized water to remove any extraneous particles. The resin was rinsed with a $10 \%$ hydrochloric acid solution to remove any existing cations, converting the resin to the hydrogen forn?. From the hydrogen form, the resin was converted to the sodium form by rinsing with a solum don of $100 \mathrm{~g}$ of sodium chloride per liter of delonized water at a rate of $31 \mathrm{~mL} / \mathrm{min}$ for 1 hour. The resin was then in a standard form for analysis.

Water Ratention Capaclty. Testing of ion exchange resirus for water retention capacity indicates the porosity of the resin. The porosity of a resin is dependent on the amount of effective cross-linking. The higher the water retention capacity, the lower the effective cross-linking. In the case of the PF -8 and -20 rosins, the water retention capacity is an indication of the amount of divinylbenzene cross-linking for the strong acid resins. That relationship cannot be quantified because of the proprietary nature of the EPICORII resins. Some loss of effective cross-linking occurs before the release of radionuclides. ${ }^{12}$ The test consisted of drying known amounts of pretreated $\mathrm{PF}-8$ and -20 styrene and phenolic cation resins in an oven at $110+5^{\circ} \mathrm{C}$ for a minimum of $18+2$ hours. The differences in weights before and after drying were used to calculate the water retention capacity. The test was performed in triplicate, and the average was calculated.

Backwashed and Sottled Deryslty. The backwashed and settled density test was developed to determine changes in effective cross-linking between new and used resins. The density is directly proportional to the amount of effective cross-linking in the resin. As previously noted, some loss of effective cross-linking occurs before radionuclides are released (Reference 12). The test consisted of backwashing a known amount of resin with delonized water for $10 \mathrm{~min}$. The resin was allowed to settle and the volume was recorded, Then, the density was calculated based on a known weight of resin in grams to a known volume of water in milliliters. The test was performed in triplicate and the average was calculated.

Salt-Splltting Capaclty. The salt-splitting capacity test is designed to show only the number of sulfonic acid groups contained in a cation ion exchange resin. A decrease in salt--splitting capacity would show a loss of functional sulfonic acid groups. The loss of sulfonic acid groups would allow the release of those radionuclides tied to those functional groups. Phenolic, carboxylic acid, and phosphonic acid functional groups also will exhibit, to some do- groe, salt-splitting capacity. The test assembly apparatus is dopicted in Figure 11. The resin was converted to the hydrogen form by flowing $10 \%$ hydrochloric acid solution over the resin at a rate of $31 \mathrm{~mL} / \mathrm{min}$. The hy. drogen form cation resin was eluted with a $50 \mathrm{~g} / \mathrm{L}$ sodium chloride solution at a rate of $31 \mathrm{~mL} / \mathrm{min}$. The elited sodium chloride solution was titrated with standard $0.10 \mathrm{~N}$ sodium hydroxide solution to determine the amount of hydrogen exchanged in the clution process. The test was performed in triplicate and the average was calculated.

Total Exchange Capacity. The total exchange capacity test is used to determine exchange capacity of cation lon exchange resins that contain functional groups in addition to, or different trom, sulfonic acid functional groups. A decrease in total exchange capacity indicates the loss of functional groups and subsequent loss of radionuclides. Different functional groups include phenolic, carboxylic acid, and phosphonic acid, The apparatus shown in Fitgure 11 was assembled, and a $10 \%$ hydrochloric acid solution was eluted through the resin to convert it to the hydrogen form. The resin was transferred to a separate flask containing $200 \mathrm{~mL}$ of standard $0.10 \mathrm{~N}$ sodium hydroxide solution. The solution also contained $50 \mathrm{~g}$ of sodium chloride per $\mathrm{L}$. The resin was allowed to equilibrate in the solution for a minimum of 16 hours, An aliquot of the solution was collected and titrated with standard $0.10 \mathrm{~N}$ hydrochloric acid solution. The adsorption of hydroxide ion by the resin in the presence of sodium chloride is proportional to the total exchange capacity. The test was performed in triplicate, and the average was calculated.

Infrared Spectroscopy. Infrared spectroscopy (IR) involves identifying the rotational and vibrational motion of atoms in a molecule induced by infrared radiation. The multiplicity of vibrations occurring simultaneously produces a highly complex absorption spectruin. The spectrum is uniquely characteristic of the functional groups comprising the molenules and the overall configuration of the atoms within a molecule. Infrared spectroscopy can therefore be used to positively ideritify a pure organic molecule, IR was used to determine if the styrene and phenolic cation resins in PF-8 and -20 ware the samo as the unirradiated styrene cation and phenolic cation resins obtained from Epicor, Inc. IR spectra of the unirradiated Epicor, Inc, resins were compared with IR spectra from PFin 8 and -20 resins to determine if any mujor changes in molecular structure of the PF -8 and -20 resins had occurred because of the high internal radiation (lose. Changes can be seen by a shift in peak 


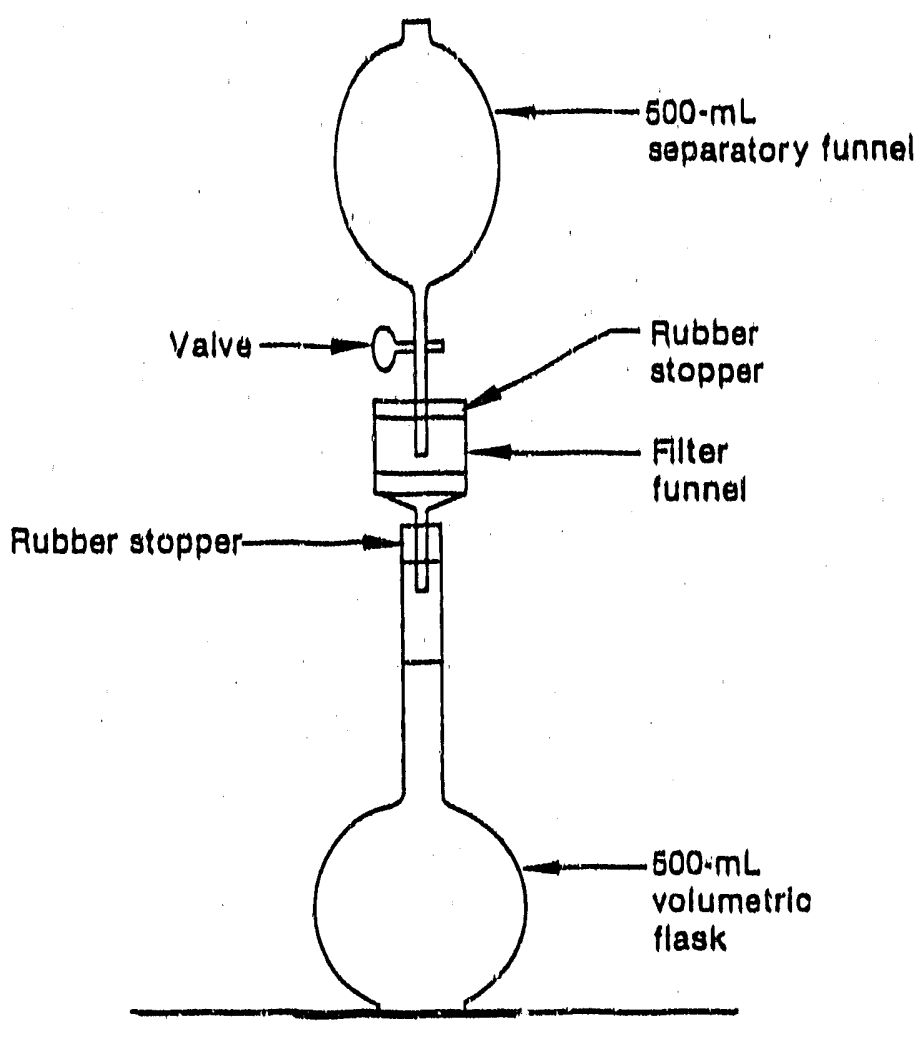

40291

Figure 11. Schematic of standard ASTM apparatus for determining salt splitting and total exchange capabilities.

location or major decrease in intensity. A change in molecular structure would indicate scission of the polymer backbone and eventual release of radionuclides.

The resin samples were drled at $110^{\circ} \mathrm{C}$ to remove excess moisture and ground in a porcelain mortar and pestle to a size of less than 80 mesh. Then, $10 \mathrm{mg}$ of resin were added to $100 \mathrm{mg}$ of dried potassium bromide (KBr) and placed in a pellet press. A compressive force was applied to the pellet press and a pellet containing the resin was obtained for IR scanning. The $\mathrm{KBr}$ pellet was placed into the sample beam of a Perkin Elmer Model 1430 infrared spectrophotometer and an IR spectrum was obtained. Results of IR analysis are presented in References 3 and 4.

Gas Chromatography. Gas chromatography (GC) is a technique where volatile mixtures of compounds can be separated into pure compounds and detected separately. This is performed by vaporizing a mixture In a heated injection port and then sweeping the gases into a $\mathrm{GC}$ colum a by using an inert carrier gas such as helium. The column is contained in a temperature pro. grammable oven. The GC column has an inert packing material coated with a nonvolatile compound. The various components in a mixture are separated by their different solubilities or affinities for the coating on the packing material. The pure compounds are detected sequentially at the end of the column. For organic materials, a flame ionization detector is typically used.

GC columns used in the EPICOR-II resin samples were: 1) A 1/8-in.-O.D. by 6-ft-long columin containing $0.34 \%$ tetranitrofluorenone as a stationary phase on Carbopack C, 2) A 1/4-in...-O.D. by 6-it-long column containing $1.0 \%$ SP-1240DA on Supelcoport, and 3) A 0.52-mm-I.D. by 30-m-long bonded phase methyl phenyl sillicon column (J. W. Scientific DB-5).

The aliquots chosen for GC analysis were the distilled water soak arid rinse solutions from the resin samples. All solutions from resin samples wero prepared for analysis by extraction with a nonaqueous solvent of either dichloromethane or hexane. The extraction allows water leachable organic analytes to be extracted into the organic phase thus affecting the separation of organic material from the highly 
radioactivo aqueous solutions. Perkin Elmer sigma IB and IIB gas chromatographs equipped with flame ionization detectors were used. Typlcal GC shromatograms are presented in References 3 and 4.

Llquild Chromatography. High-performance liquid chromatography (HPLC) is a technique by which a liquid or solid organic soluble mixture is separated into its individual components by differences in affinities of the components toward either the liquild (mobile phase) or the functional groups on the stationary phase of a separator column. For the EPICOR-II samples, a 15-cm C-18 (octadecyldimethylsilyl) column was used. The mobile phase was a mixture of acetonitrile and water. All solutions from resin samples were prepared for analysis by extraction with non. aqueous solvent of either dichloromethane or hexane. Aliquots of the extracts of the soak and rinse solutions from PF-8 and -20 were injected into a Kratos HPLC, using a UV-VISIBLE detector, and HPLC chromatograms were obtained. Typical HPL.C chromatograms are presented in References 3 and 4.

Suporcritical Flulds Chromatograph. Supercritical fluid chromatograph (SFC) was also used in the third sampling. This is a chromatography tech. nique in which the mobile phase has been raised above its critical temperature and pressure. At this point, called the critical point, the mobile phase is neither a gas nor a liquid, but has pmperties of each. Separations are made based on the different solubilities of analytes by changing the density of the mobile phase. This technique lends itself well for thermally labile compounds and larger molecular weight polymeric materials, which cannot be run using other chromatography techniques. All solutions from resin samples were prepared for analysis by extraction with nonaqueous solvent of elther dichloromethane or hexane. Extracted liquid samples for the EPICOR-II resins were analyzed using a $10-\mathrm{m}$ SB--Phenyl-50, 100 micron ID, 0.25 micron film thickness capillary column. Carbon dioxide was used as the mobile phase and an isothermal $\left(100^{\circ} \mathrm{C}\right)$ pressure program was run starting at 100 $\mathrm{atm}$, and going $10375 \mathrm{~atm}$, at a rate of $5 \mathrm{~atm} . / \mathrm{min}$. The results of SFC are included in the "Results and Inter" pretation" section of the report.

Barlum Chlorlde Preclpitation for DeterminatIon of Sulfonic Acld Groups. It has been shown that the EPICOR-Il cation resins are sulfonic acid, divinylbenzene, styrene type resins (Reference 8). The high internal radiation dose recelved by those resins could cause loss of the functional groups (sulfonic acid) and release of radionuclides tied to the lost functhonal groups. The loss of functional groups would cause an increase in the sulfate concentration of the delonized water snak and rinse solutions taken from samples $P F-8$ and -20 strong acid cation resins.

A $25 \mathrm{~mL}$ aliquot was removed from each solution and transferrod to a graduated cylinder. Enough barium chloride was added to the solution in the graduated cylinder to ensure an excess amount. The contents of the cylinder were agitated and allowed to stand a minimum of $3 \mathrm{~min}$. A portion of the solution from the graduated cylindor was transferred to a $1-\mathrm{cm}$ (path length) polyethylene sample cell and placed into a visible spectrophotometer set at a wavelength of 420 nin. The absorption values of the solution were obtained and compared with absorption values of standard sulfate solutions. Results of those tests are reported in References 3 and 4.

Inductlvely Coupled Plasma - Atomlc Emloslon Spectroscopy for the Determination of Sultur (ICP-AES). ICP-AES was used in the third sampling for the measurement of lost sulfonic acid groups from the strong acid cation samples. ICP-AES is a technique based on the measurement of light emitted from excited atoms and lons in a plasma. A solution to be analyzed is nebulized into the spray chamber of the sample introduction system of the ICP-AES. Some of this solution goes through a plasma torch where the sample is desolvated, atomized, and (for some elements) lonized. Outer shell electrons are excited by the high-temperature plasma and when these excited atoms and lons decay back to the ground state electronic configuration they emit photons of radiation characteristic of the elements that are contained in the sample. This light is separated by wavelengths in the monochromator section of the instrument and detected by a photomultiplier tube. The amount of light detected is directly proportional to the concentration of the analyte in the solution.

This technique was used to measure sulfur in soak, deionized water rinse, and elution solutions of the resin samples. Sulfur detected in these samples will be in the form of sulfate, which originates from the loss of the sulfonic acid groups on the strong acid cation resins. By combining the amount of sulfur found in all soluthons that contacted each particular resin type, it is possibie to get an idea of the total sulfonic acid group loss yer resir sample. This information is combined in a table in the "Results and Interpretation" section of this publication.

Scanning Electron Microscopy. In order to determine physical conditions of resin samples from $\mathrm{PF}-8$ and -20 , scanning electron microscope (SEM) photomicrographs were obtained of the resins at difforent 
magnification levels, The photomicrographs allowed examination of the resins for craoks, bead breakage, bead softening, agglomeration, and so forth. Most types of physical damage of the resins would not allow the release of radionuclides, but the extent of resin degradation can be estimated. Random specimens were extracted from the resin samples after radionuclide elution, Photomicrographs were made of entire specimens and interesting features were examined more closely. The photomicrographs presented in this report and References 3 and 4 represent typical damage observed.

The irradiated resin samples from the third sampling were attached to an SEM planchot by placing a small aliquot of the resin beads on a wet coat of conductive carbon paint. This allowed for conductance of the electrons from the samples and no gold spattering was found necessary (as was performed wilth provious sam- ples), SEM photomicrographs were obtained of the resins and are included in this report.

Gamma-Ray Spectroscopy. Gamma-ray spectroscopy was used in the third sampling to determine the total amount of Cs-134 and Cs-137 present in the resin samples. Gamma ray spectroscopy is based on the measurement of the characteristic energy of the gamma rays produced during radioactive decay. Each isotope emits gamma rays with specific energies. By using a energy dispersive detector it is possiblo to identify the species of radioactive material. And by calibration using a roproducible sample geometry, it is possible to perform quantitative analysis.

An aliquot of each of the soak, rirse and elution samples were submitted to the Radiation Measurement Laboratory for counting. The results of this analysis are presented in the "Results and Interpretation" section of this report. 


\section{RESULTS AND INTERPRETATION}

The unirradiuted resins showed no appurent change from previous analyses (References 3,4 , and 8 ). Because of the age (7 years old) of the unirradiated resins, they might be expected to show some degradation due 10 aging. The irradiated resins from PF-8 and -20 also would be expected to show some degradation due to age (9 years old), ${ }^{2,12}$ The unirradiated resins showed little or no degradation because of age; therefore, in this study, any degradation of the irradiated resins was presumably from radiation damage and not from other caluses. Other causes of degradation would be huxuling/ mechanical damage and freezing. A review of the history of profilters $\mathrm{PF}-8$ and -20 shows that the ion exchange media were exposed to subfreezing lemperatures while stored at the INEL. Hown ever, exanninations, using the unirradiated resins to determitic freezing damage, have shown that none has occurred. Also, handling was held to a minimumi as a result, dimage should have been minimal.

During sample preparation, the resins were soaked and then rinsed in deiontzed water. It was difficult to produce flow through the resin columins containing samples of $P F-8 \# 1, P F-8 \# 3$ and $P F-20$ during rinsing indicating the extent of degradation. Sediment layers were evident in those samples and very low flow was obtained. Those samples were swirled in deionized water to remove sediment and improve flow. Further indication of degradation was shown by the release of radionuclides to the sonk and rinse water, as shown in Table 2. The more highly nuclide loaded samples from PF-8 show significant radioactivity in the soak and rinse waters (Table 2). That would not have occurred with undegraded resins. Some measurement differences are noted between sumplings; these differences were caused by different olution and measurement techniques.

The soak water from each of the samples was brown in color and sediment was observed in PF-8\#1, $P F-8 \# 3$, and PF-20. This sediment was obviously lighter than the resin as it floated to the surface. It is somewhat difficult to speculate as to the composition of this material. It is not likely that the sediment

Table 2. Radioactivity of resin soak, rinse and acid composite samples in first, second, and third sumplings

\begin{tabular}{|c|c|c|c|}
\hline Sanple & $\begin{array}{l}\text { First Sumpling } \\
\text { Measurement at Contact } \\
(\mathrm{mR})\end{array}$ & $\begin{array}{c}\text { Second Sampling } \\
\text { Measurement at Contact } \\
(\mathrm{mR})\end{array}$ & $\begin{array}{l}\text { Third Sampling } \\
\text { Measurement at Contact } \\
(\mathrm{mR})\end{array}$ \\
\hline $\mathrm{PF}-8 \# 3-24-\mathrm{h}$ sonk" & No resin sample & $50^{d}$ & $50^{d}$ \\
\hline PF-8B3--Rinseb & No resin sumple & $30^{\mathrm{d}}$ & $500,1300,1000^{d}$ \\
\hline PF-8\#3--Acil compositec & No resin sumple & $500^{d}$ & $1000,140^{d}$ \\
\hline PF-8\#1-24-14 soak & $100 x^{k}$ & $40^{\mathrm{d}}$ & $35^{\mathrm{d}}$ \\
\hline PF-8\#1-Rins:ceb & $35^{\mathrm{d}}$ & $30^{d}$ & $200,500^{d}$ \\
\hline PF $-8 \# 1$-Acicl compositec & $800^{4}$ & $500^{d}$ & 210()$^{d}$ \\
\hline PF-8\#2-24h sonk" & 45 & 5 & 25 \\
\hline PF $-8 \# 2-\ldots$ Rinset & 100 & 6 & 10 \\
\hline PF-8\#2-Acid compositec & 80 & 35 & 2300 \\
\hline$P F-20-24-h$ souk" & $2^{d}$ & $25^{\mathrm{d}}$ & $60^{d}$ \\
\hline$P F-20$-_Rinsseb & No sample & $15^{\mathrm{d}}$ & $500,40^{d}$ \\
\hline PF-20 _-Acid Composilec & $80^{4}$ & $35^{\mathrm{d}}$ & 290 \\
\hline
\end{tabular}

a. $24-\mathrm{h}$ soak used a total of $100 \mathrm{~mL}$ demineralized water, All $100 \mathrm{~mL}$ were counted.

b. Rinse used a total of $100 \mathrm{~mL}$ demineralized water. All $100 \mathrm{~mL}$ were counted.

c. Acid composite used a total of 5 or $6 \mathrm{~L}$ of 10 percent hydrolic acid, $200 \mathrm{~mL}$ were counted in the first sampling, $500 \mathrm{~mL}$ were counted in the second sampling, and 4000 and $2000 \mathrm{~mL}$ were counted in the third sampling.

d. The resin sample was agitated to promote flow of liquid through the sample. 
was dirt or particles of zeolite as those materials are more dense than organic resins, It is possible that the sediment was decomposed polymer material. Samples were taken from all delonized water soak, rinse, decant, and elution solutions to look for soluble organic products. And while none were observed, it is possible that this material was not water soluble and therefore not found in any aqueous solutions.

\section{ASTM Tests}

Table 3 presents results of tho following ASTM test performed on unirradiated and irradiated resins from the third sampling: (a) water retention capacity, (b) backwashed and settled density, (c) salt-splitting capacity, and (d) total exchange capacity.

The differences between ASTM tests performed on unirradiated Epicor, Inc., resins and PF-8\#1, PF-8\#3, $P F-20$, strong acid cation resins and $\mathrm{PF}-8 \# 2$ phenolic resin from the third sampling are presented in Table 4. The differences were calculated using measured data shown in Table 3. The results show that resin samples receiving more radiation dose exhibii greater changes in measured properties. Water retention capacities increased with dose; while backwashed and settled density, salt-splitting capacity, and total exchange capacity decreased. Increase in water retention capacity indicates a loss in effective cross-linking, the amount of loss being deperident upon radiation dose (Reference 12).

It is also possible that water retention capacity has increased due to the increase in surface area caused by the extensive resin bead cracking observed in the electron photomicrographs. ${ }^{3,4} \mathrm{~A}$ decrease in backwash and settled density also is an indirect indication of loss of effective cross-linking, which can lead to eventual loss of radionuclides (Reference 8). The decrease in saltsplitting capacity of the irradiated resins is an indication of loss of functional groups, sulfonic acid, and accompanying loss of radionuclides (Reference 8). During the second sampling, a slight increase in salt-splitting capacity was observed for PF-20. This would indicate that $\mathrm{PF}-20 \mathrm{had}$ reached the threshold needed for degradation to begin during the second sampling (References 2 and 12). Furthermore, the higher radiation doses to the PF $-8 \# 1$, and PF-8\#3 resins were the cause for the decreases in total exchange capacities as the radiation damage exceeds the contribution from oxidation. It was found in the review of Reference 2 that oxidation of the polymer chain will cause an initial increase in total exchange capacity followed by a decrease as the radiation damage exceeds that contribution. The decrease in total exchange capacity should result in the loss of radionuclides from the exchangc sites.
The ASTM parameters for $\mathrm{PF}-8 \# 2$ show that differences between unirradiated and irradiated phenolic cation resin samples are increasing, similar to the changes observed for the styrence cultion resins. There has been a steady increase in the water retention capacity, and a steady decrease in the total exchange capacity (Table 4). This indicates that the resins are degrading. One must be guarded in making conclusions about the phenolic resins in these tests as the samples of $P F-8 \# 2$ resins were unavoidably contaminated with styrene resins. As much as $19 \%$ of the mass of the $\mathrm{PF}-8 \# 2$ sample was actually styrene resin beads.

At the time of the third sampling, all 0 : the resins were showing significan degradation. Table 4 shows the amount of change of ASTM parameters between the unirradiated and irradiated resin sumples. This table was prepared to show a history of the three samplings and the amount of change in the degradation of a resin type in relation to radiation dose. There is some difference in the unirradiated resin sample data from the previous two samplings compared with the last sampling. Although the resin sample was 7 years old at the time of testing, most of the deviation in the analysis of the unirradiated resins is attributed to the fact that different analysts performed the work on the third sampling than did the first and second sarnpling. The ASTM procedure recognized the fact that multi-operator precision is less than that of the single operator. Although age may be a factor in part of the measurement difference, the real significance between the irradiated and the unirradiated resins is the difference in the ratio of unirradiated verse irradiated resin in any one sampling. This difference is largely due to degradation caused by radiation damage. Because all of the irradiated resins and unirradiated resins were tested at the same time, all of the samples were treated identically. This helped eliminate variations caused by handling and experimental condition differences (e.g. humidity on the day that the water retention capacity was performed).

The results of these analyses are graphically presented in Figure 12 where the change in total exchange capacity with increase in radiation dose is presented. Probably the most important characteristic of ion exchange media is total exchange capacity. This figure shows the marked decrease in exchinge capacity as the resins received more radiation doses. While there is some separation of the curves for Samples $P F-8 \# 1$ and \#3 from PF-8 \#2 (phenolic) and PF-20, the No. 1 and No. 2 sample curves are very close and all four exhibit common shapes. Primary differences in these data were introduced during measurement of radiation doses listed in Table 1. 


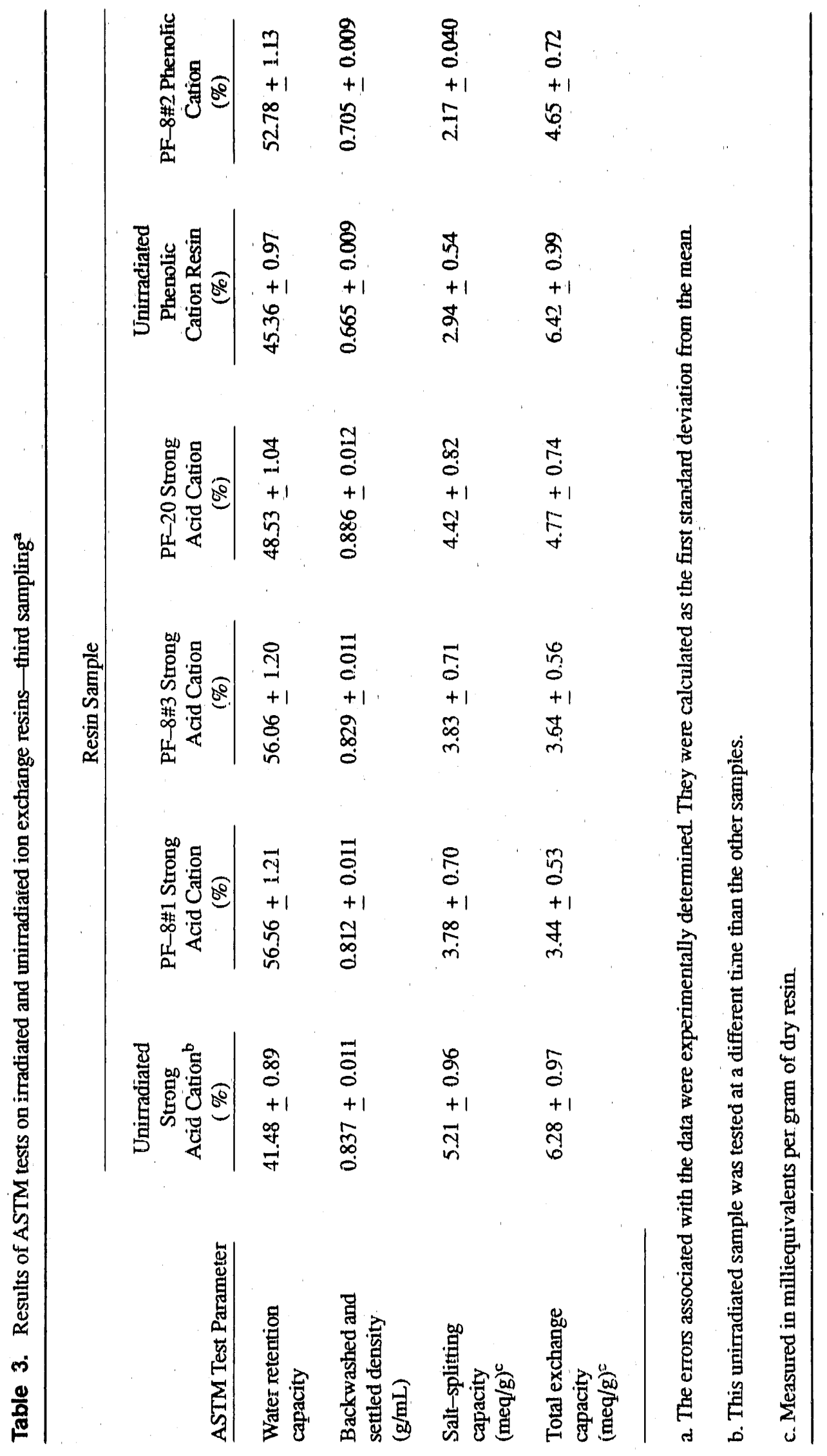




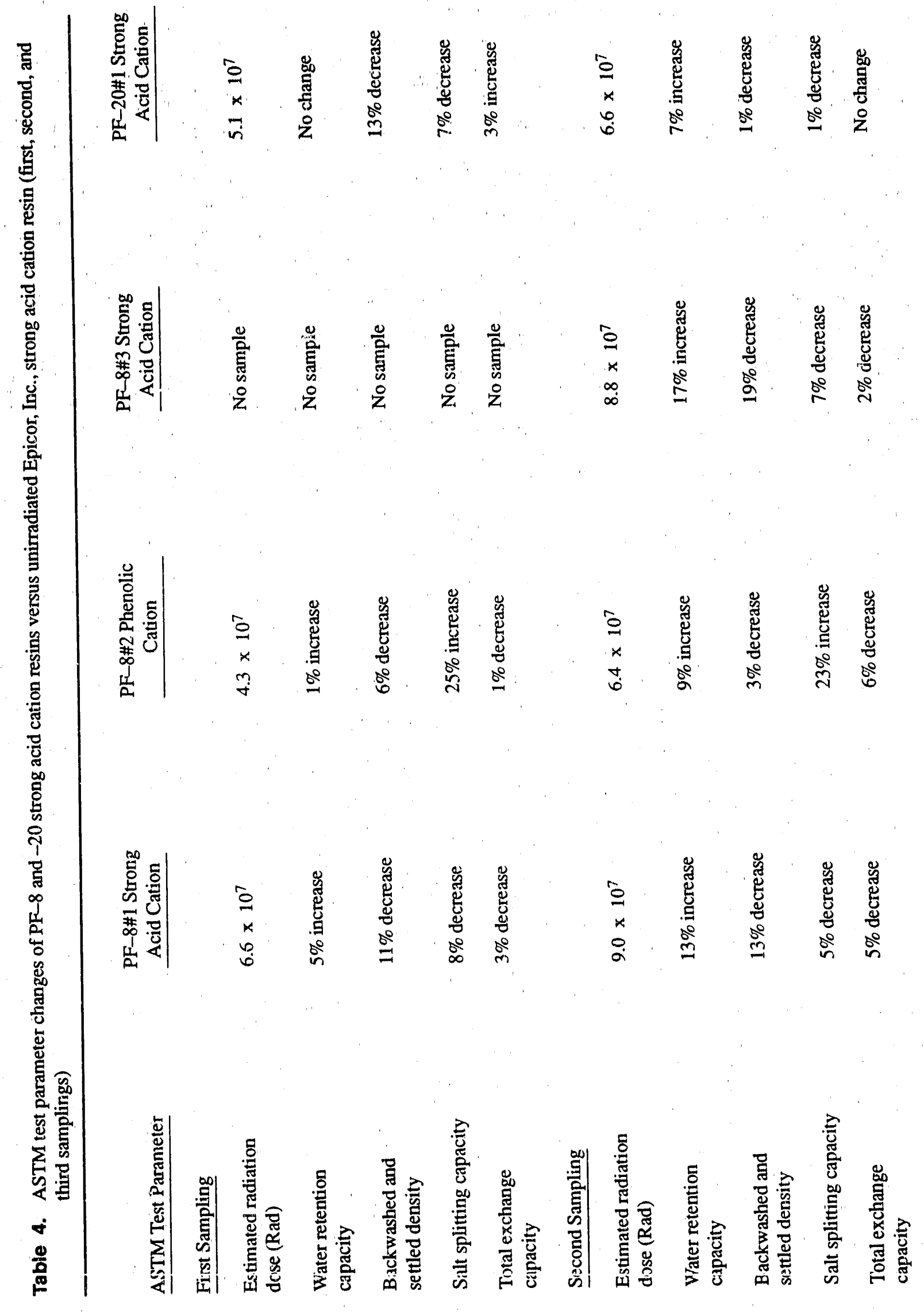




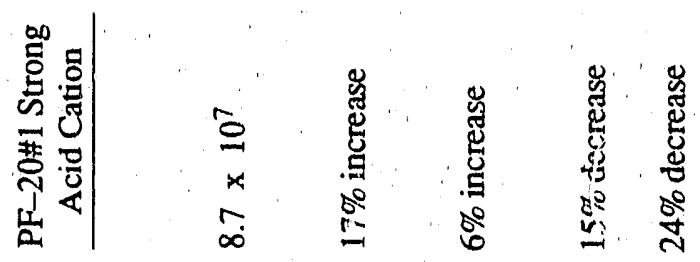

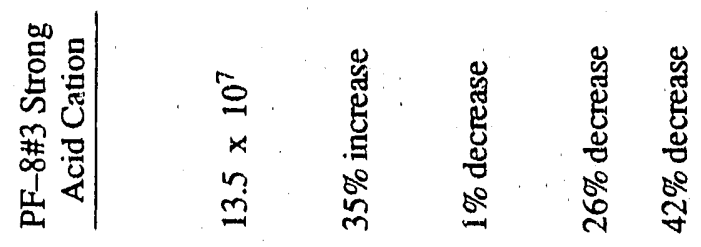

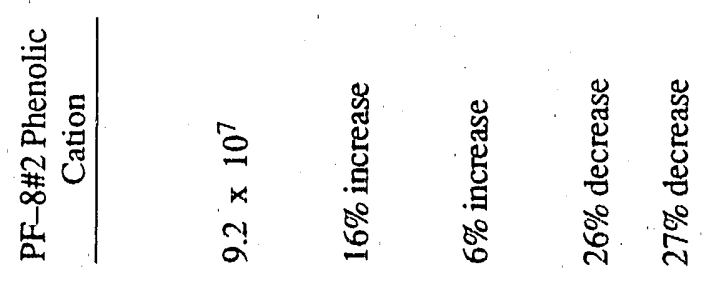

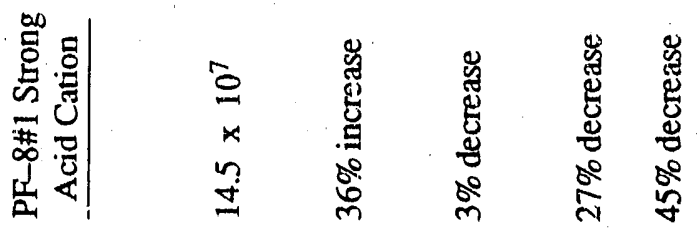

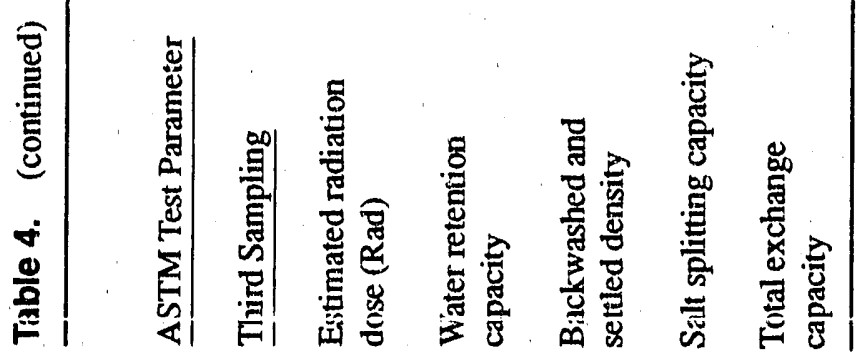




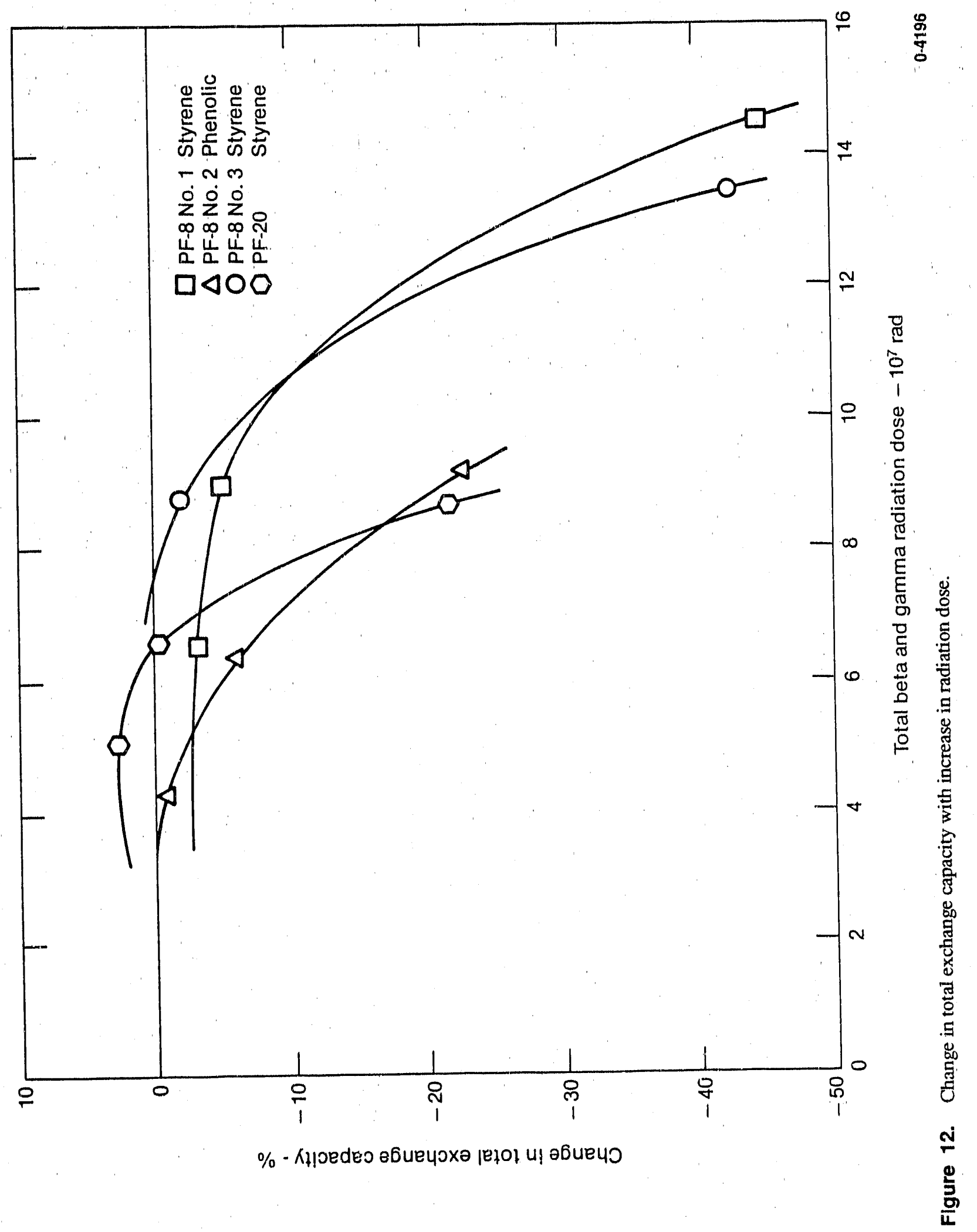




\section{Infrared Spectroscopy}

The infrared spectroscopy performed in the first and second sampling (References 3 and 4) was not used for the third sampling. Infrared spectroscopy is not a very sensitive technique for measuring small changes in a chemical species. Thus the changes such as the loss of sulfonic acid groups, which have been measured by other techniques to be on the order of a few percent of the total amount present, would not be readily apparent on the infrared spectra.

\section{Gas, Liquid, and Supercritical Fluids Chromatography}

All the chromatography methods are accepted techniques for detection and analysis of organic materials. Each of the techniques have strengths and weaknesses, but when combined, as was done for these resin analyses, they become a very powerful set of techniques that could detect most organic material present. The sensitivities vary for each of the techniques, but the detection of at least ppm levels of organic material is within the capabilities of each of the techniques.

All of the soak, pre-elution rinse solutions, and decant solutions were tested for organics by first ex tracting the aqueous solutions with hexanes and then analyzing the extracts with the various chromatography techniques. No detectable organic materials were observed in any of the chromatography experiments. This is an indication that any organic degradation products of the polystyrene divinylbenzene where not soluble in the deionized water solutions and hence not extracted into the hexanes. One can then make the conclusion that organic decomposition products are expected to stay with the intact resin beads.

\section{Determination of Sulfate}

In the first two samplings, a barium chloride precipitation was performed to determine the amount of sulfate present in the soak solutions. In the third sampling, this technique was replaced with ICP-AES. Sulfur was found in the aqueous solutions taken from resin samples (it is assumed that all sulfur is in the form of sulfate). The fact that sulfates are present in substantial concentrations demonstrates that the strong acid cation resins are losing functional groups that are responsible for holding radionuclides on the resins. The results of the ICP-AES analysis for sulfur is presented in Table 5.

The phenolic resins contain no sulfonic acid groups; therefore, the distilled water soak samples should show no sulfate (Reference 8). However, some sulfate was detected in the phenolic sample, $\mathrm{PF}-8 \# 2$, because a small amount of strong acid cation was collected with the phenolic resin due to the proximity of these resins in the prefilter.

It is difficult to determine any trend in sulfonic acid group loss from previous samplings because the actual conditions under which the samples were obtained changed significantly from the first to the third sarnpling. For example, during processing of the third sampling, it was very difficult to get any of the soak water through the column when the columns flowed relatively well in the first sampling. Also, water added to the prefilter beds during resin coring could have displaced some sulfates. The total sulfur lost from the resins was determined in the third sampling by summing up all of the sulfur present from all of the soak, rinse, and elution solution ICP-AES analyses. Measurements of $\mathrm{pH}$ were taken of all solutioris and in all cases they were less than 3 .

Table 5. Sulfate determined in aqueous solutions from resins by inductively coupled plasma-atomic ernission spectroscopy, third sampling

All Aqueous Solutions

From Resin Sample No.

PF-8\#1

PF-8\#2

PF-8\#3

$\mathrm{PF}-20$

Ünirradiaie Resin
(Milligrams $\mathrm{SO}_{4}^{2-} / 100 \mathrm{~mL}$ Resin Sample)

25

4

63

37

0.9 


\section{Scanning Electron Microscopy}

The SEM photomicrogruph of the unirradiated strong acid cation resin from Epicor, Inc., is presented in Figure 13. Figures 14 and 15 are photomicrographs of strong acid cation resin from the third sampling of PF-20. Figures 16, 17, and 18 are photomicrographs of strong acid cation resin from PF-8\#1. Figures 19 and 20 are photomicrographs of strong acid cation resin from $P F-8 \# 3$.

In comparison of Figures 1.4 and 15 with photomicrographs taken from the second sampling (Reference 4) a damaged bead can be observed where none were before. That bead appears to contain a crater also. This appears to correlate with the significant changes in degradation observed this sampling. The strong acid cation resins from $\mathrm{PF}-8$, as in prior samplings, show a lot of bead cracking and breakage. The type of breakage appears different than one would expect for purely mechanical damage. The photomicrographs Figures 16 and 17 show several types of bead fracture similar to those seen in previous examinations (References 3 and 4). The photomicrograph of the PF-8\#1 sample in Figure 18 shows concentric ring type cracking not seen before. The photomicrogriph of PF-8\#3 in Figure 19 exhibits a number of damaged beads. The bead shown in Figure 20 has been indented by surl ounding beads indicating the bead structure has soffet ed, The bead has also fractured. Few of the resins indicate a smooth surface break. Most of the broken resin beads show a ridged surface on the fracture plane (Figures $13,17,18$, and 20). A number of damaged bead fragments can be seen in the various photomicrographs. It appears that the beads first crack, then eventually fall into fragments. Most of the damage to resin beads observed in the three samplings of EPICOR-II resins has been unusual and not relatable to normal physical damage associated with pump or vacuum transfer or other mechanical damage.

The photomicrographs of $\mathrm{PF}-8 \# 2$ are less dramatic. The unirradiated phenolic resin is shown in Figure 21 . Figure 22 and 23 show the irradiated resin sample. One small crack can be observed in Figure 23 and this was the only crack observed in the phenolic resin sample. The phenolic resins have a different chemical backbone structure than the strong acid cation resins which are styrene divinylbenzene, and therefore exhibit a different physical behavior.

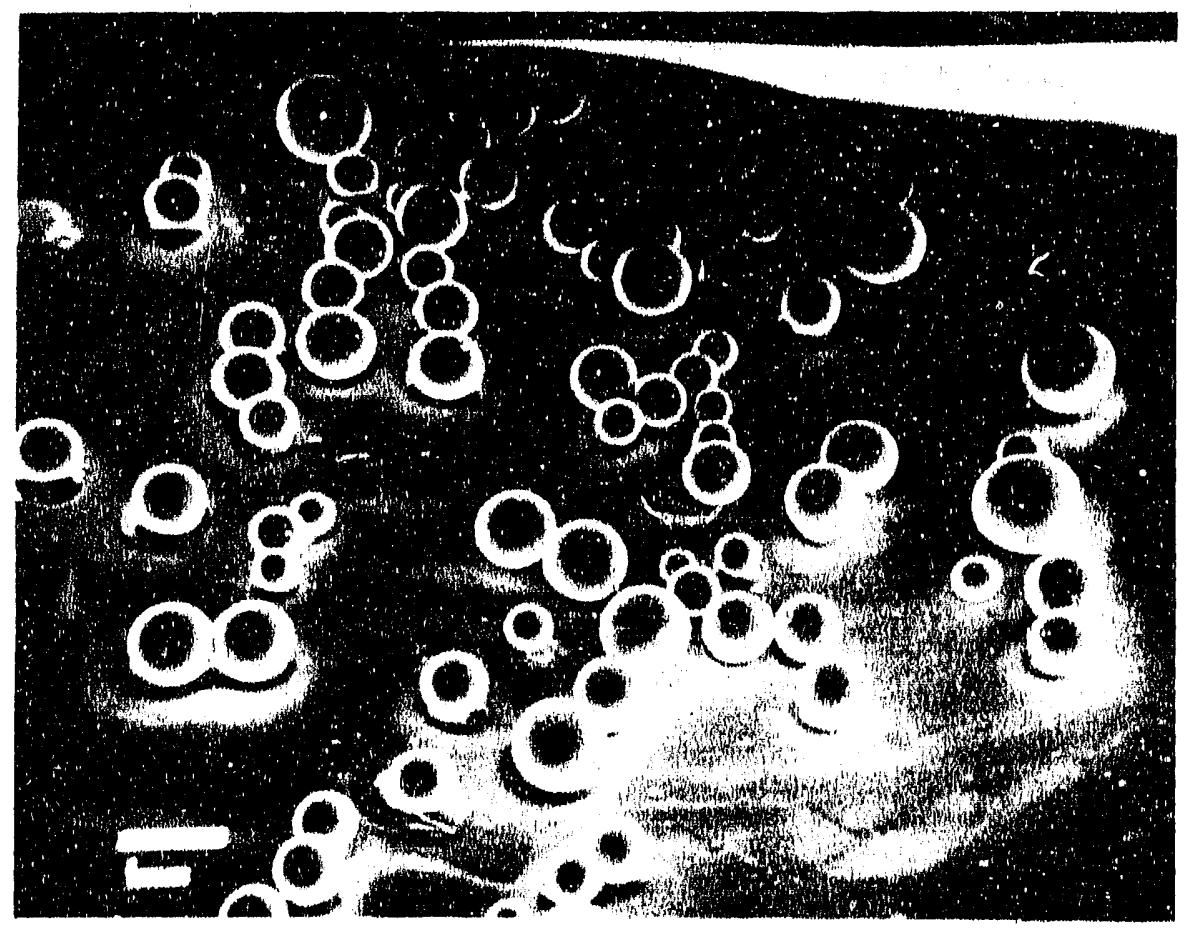

Figure 13. SEM photomicrograph of unirradiated Epicor, Inc. strong acid cation resin at 12 magnification. 


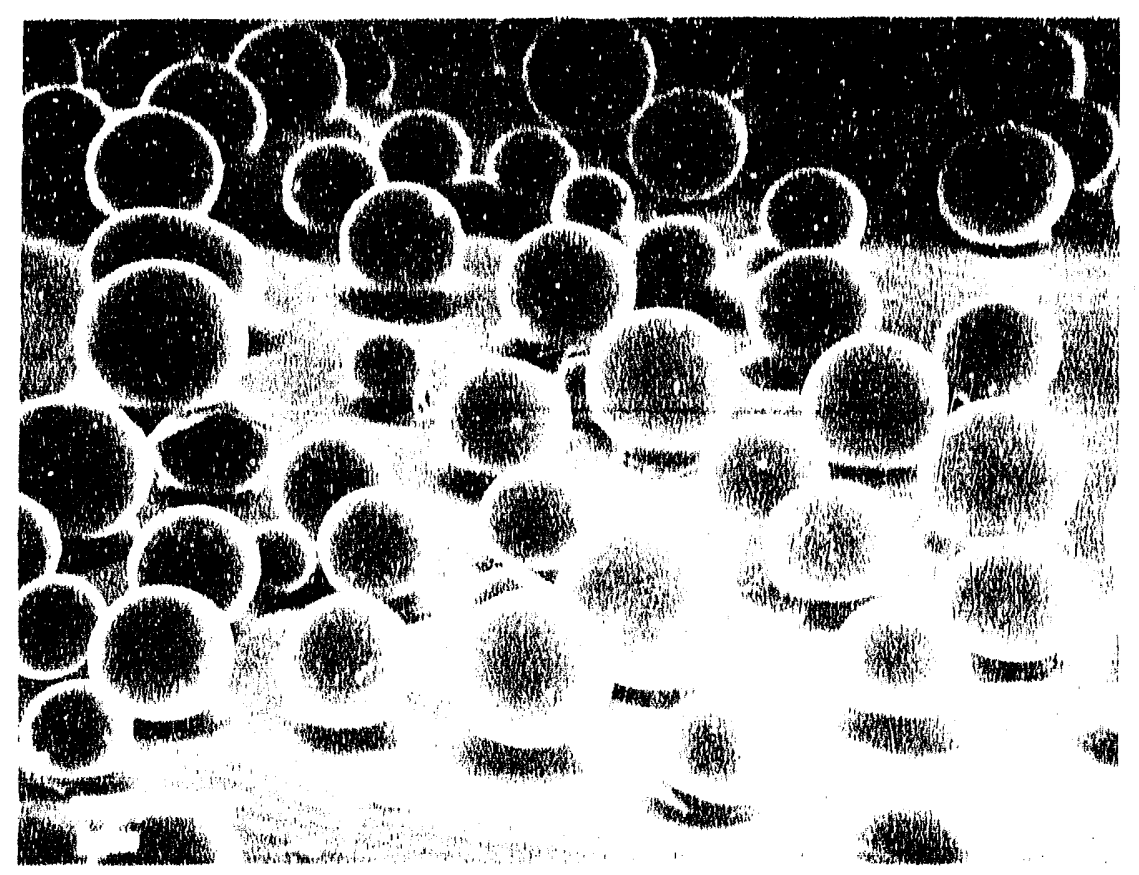

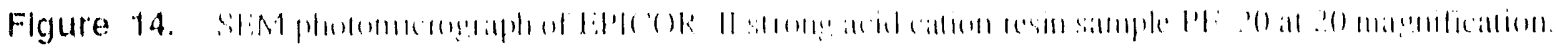

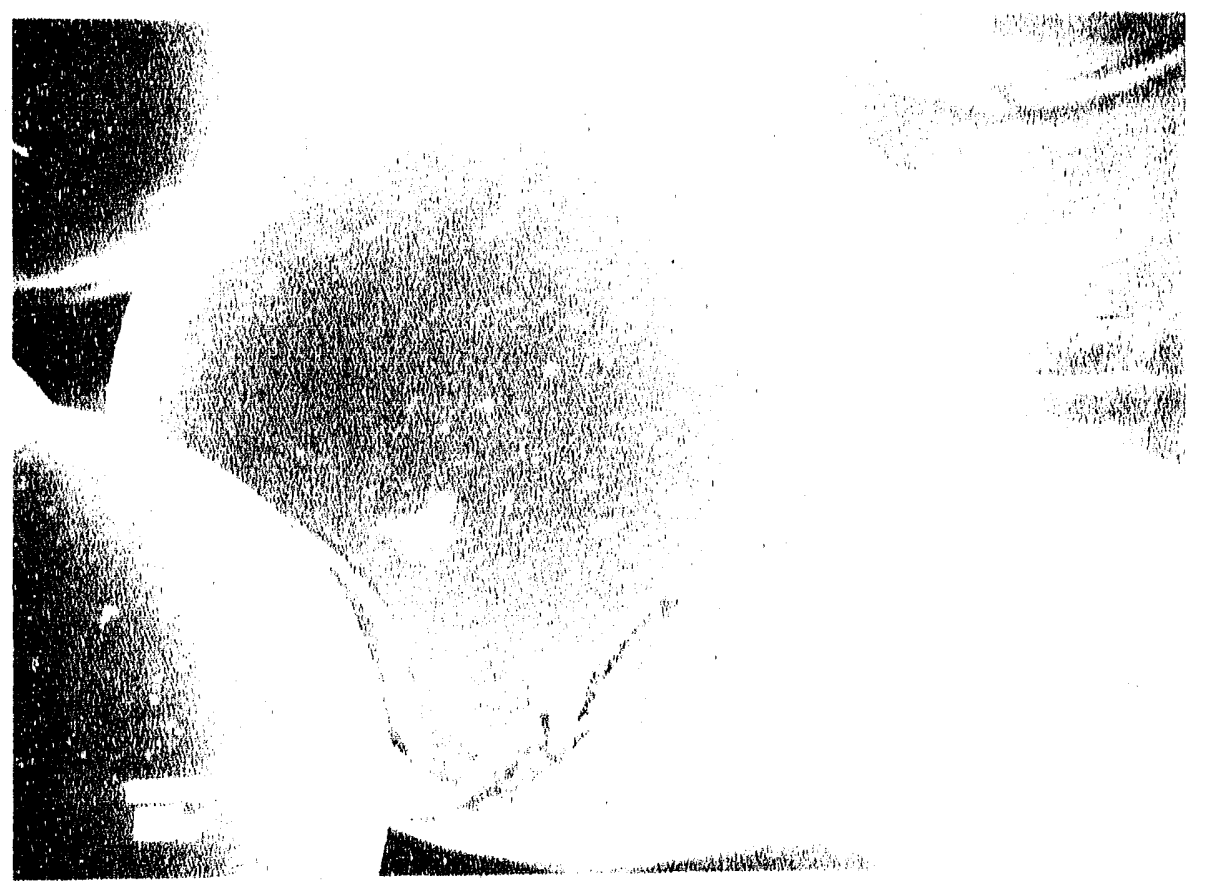

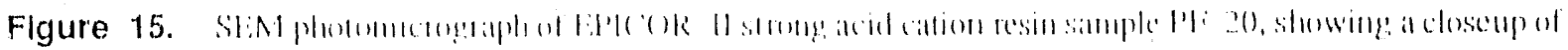

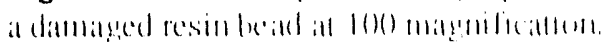




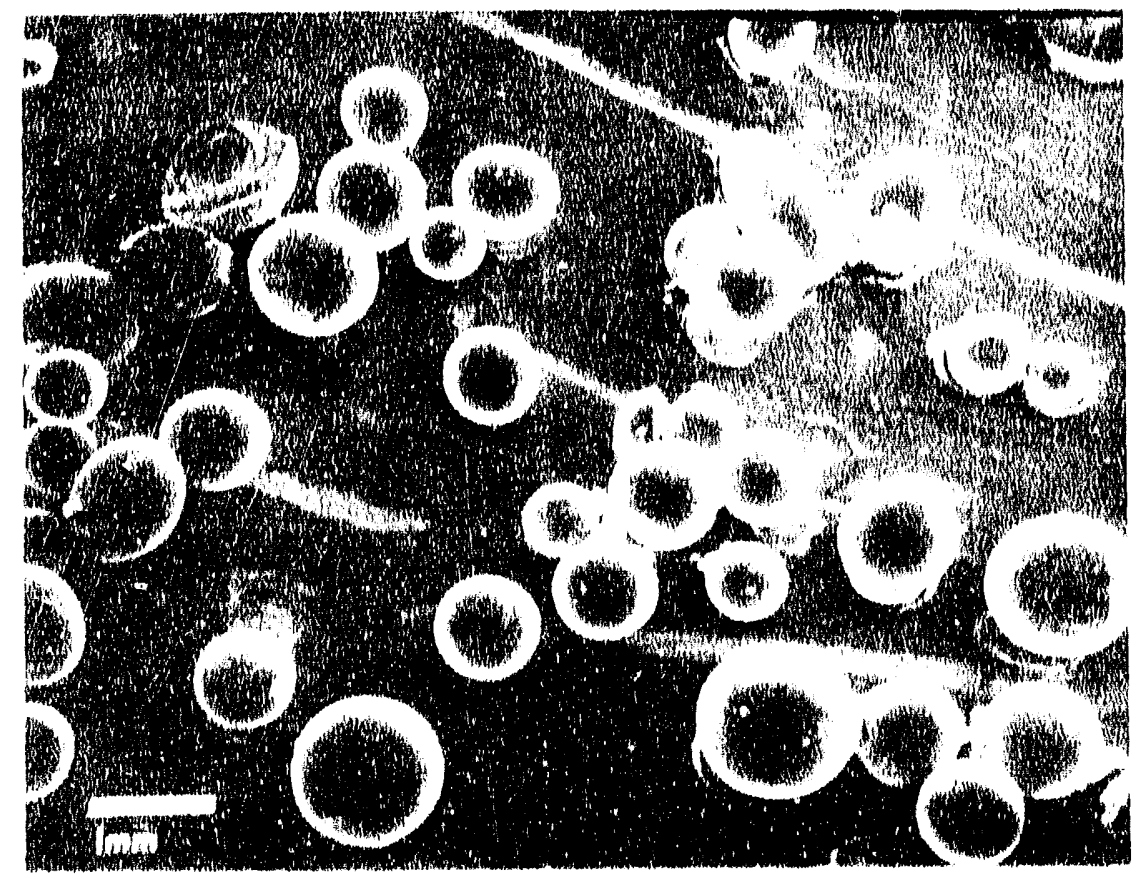

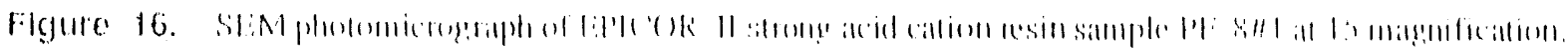

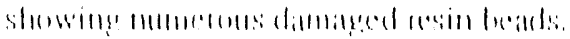

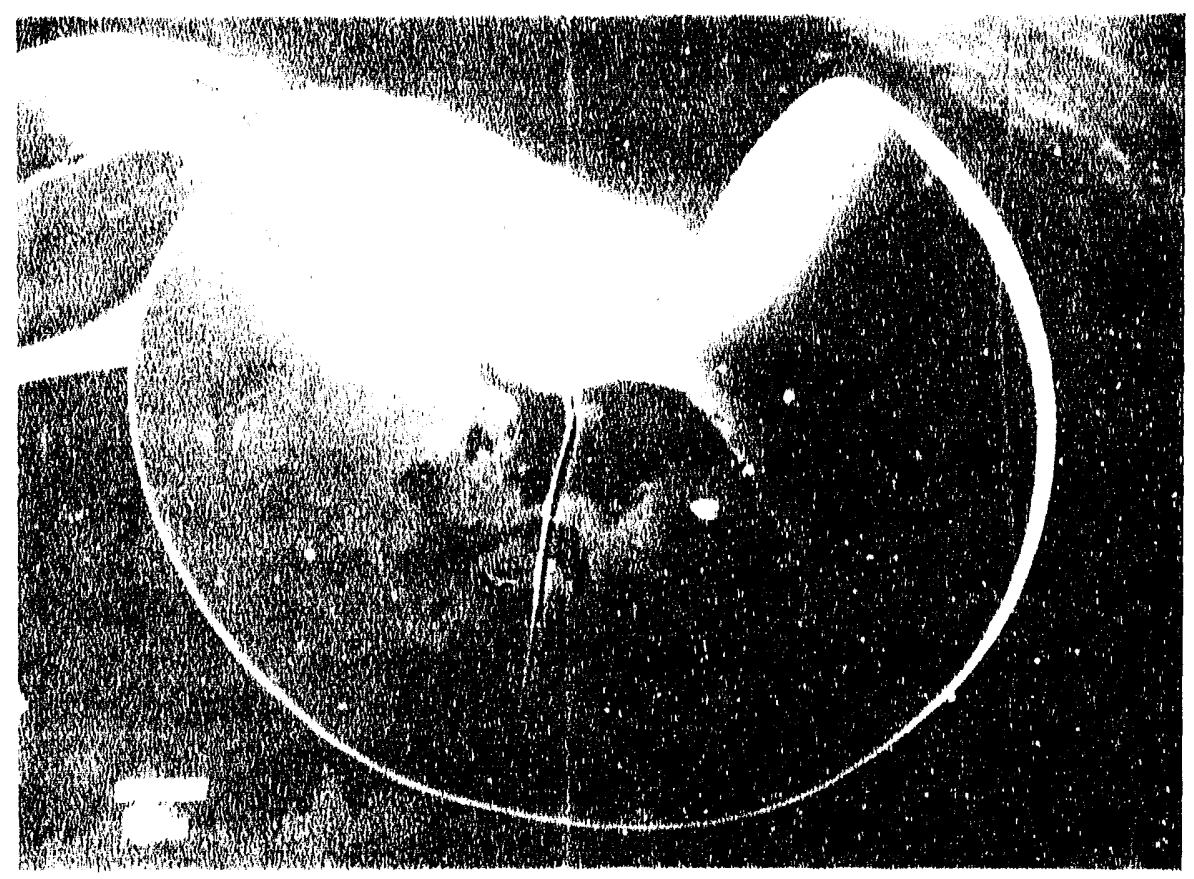

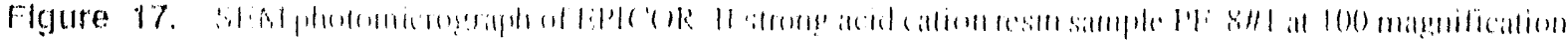

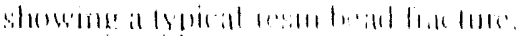




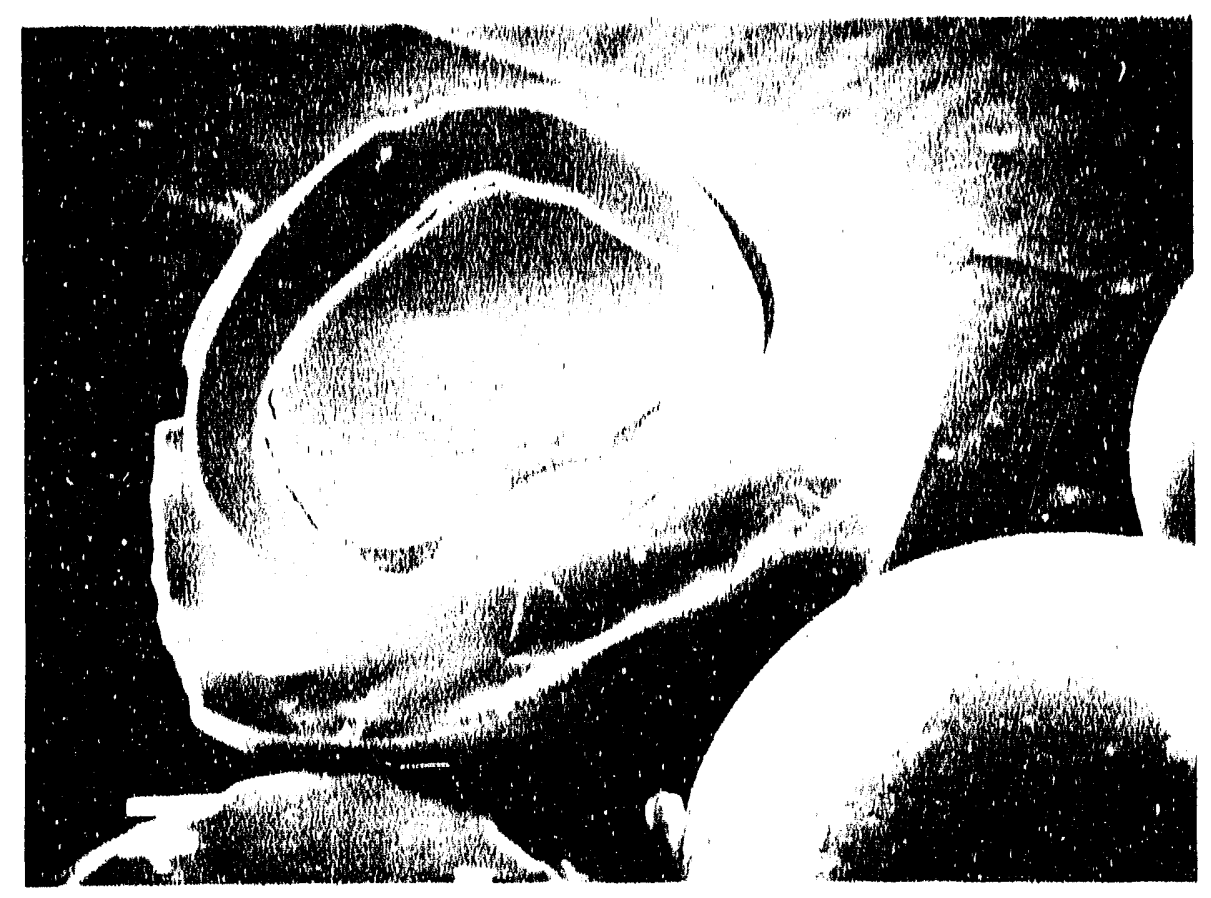

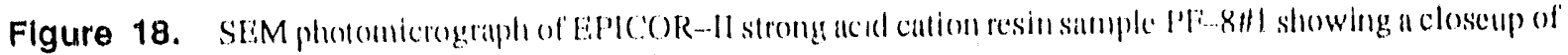

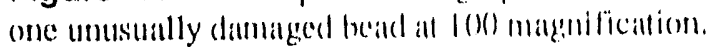

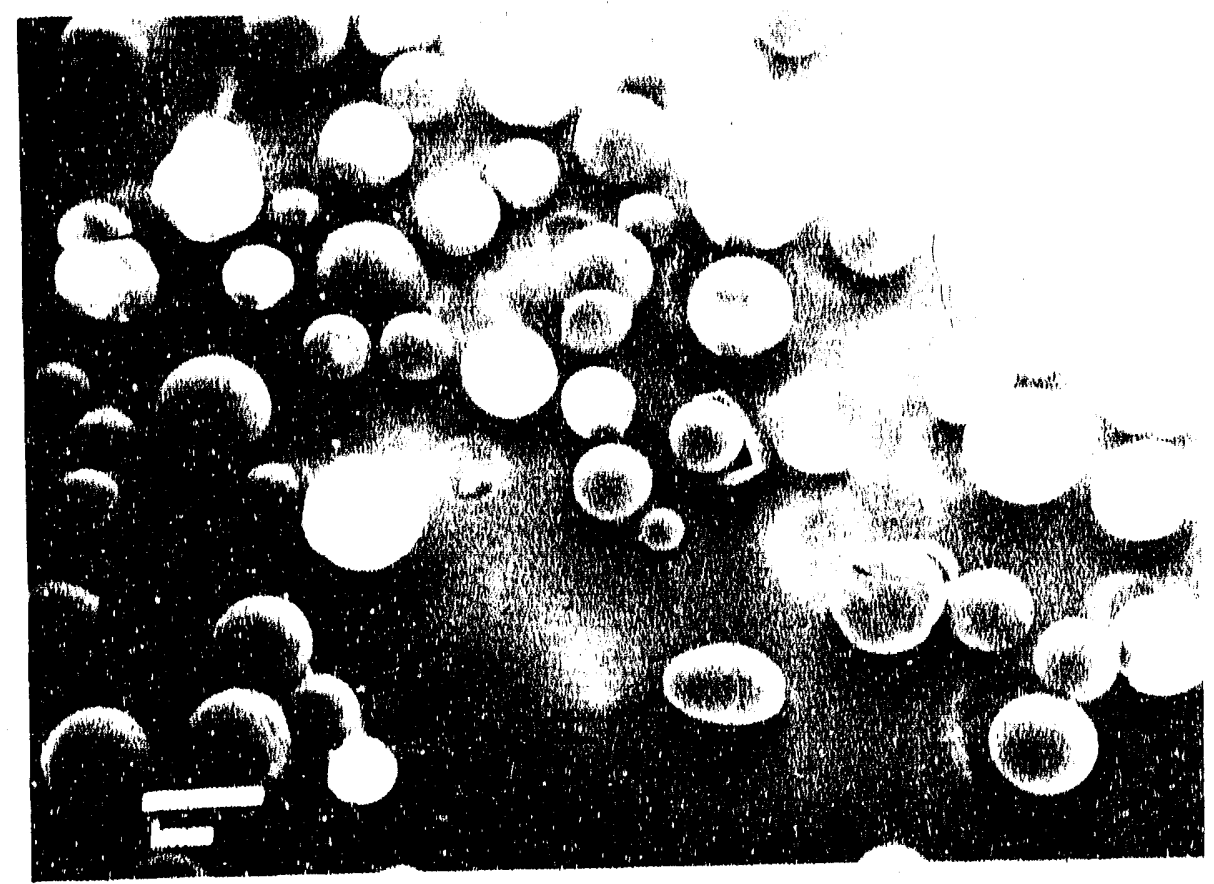

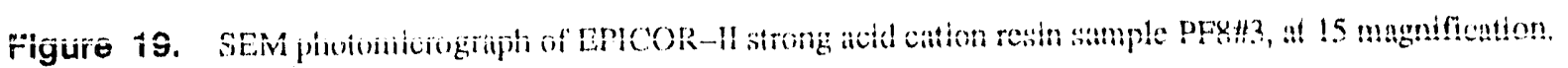



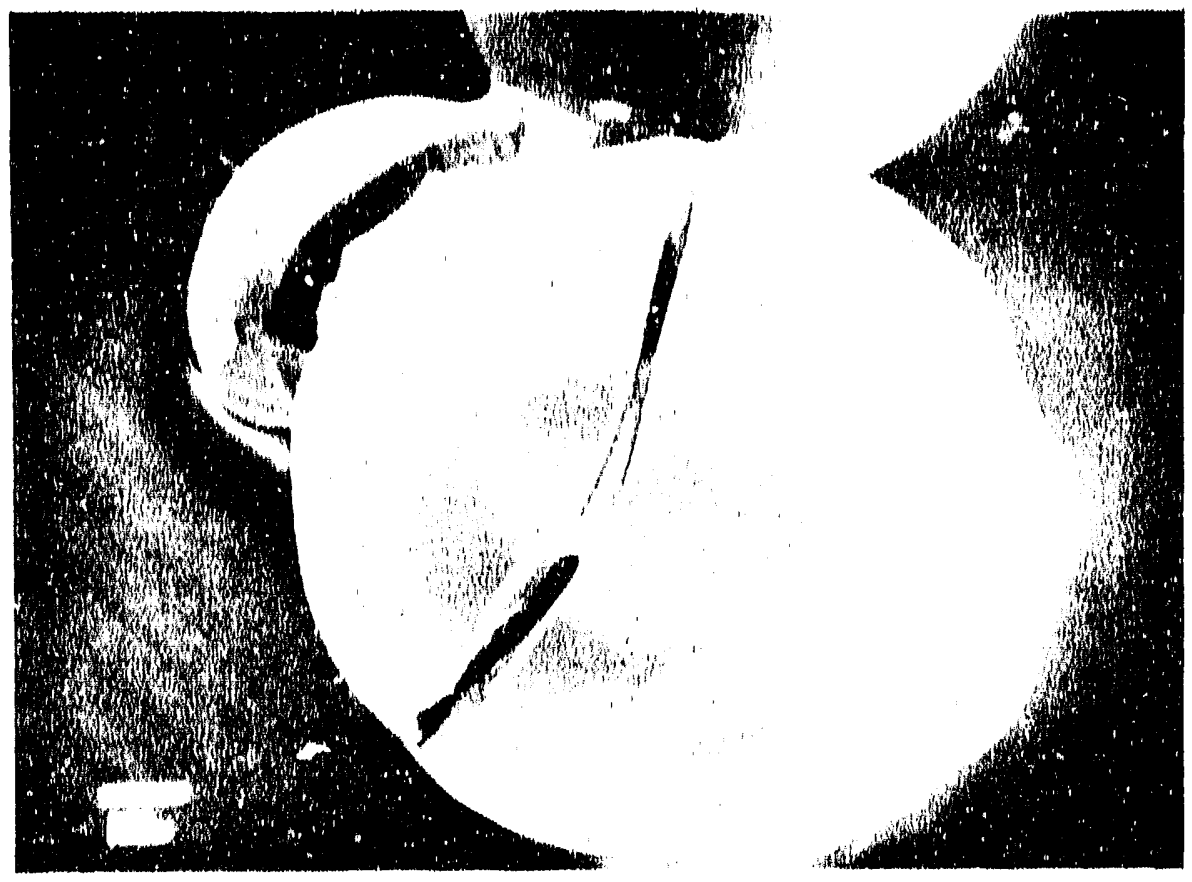

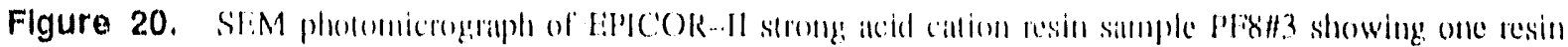

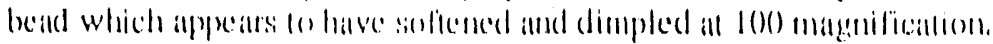

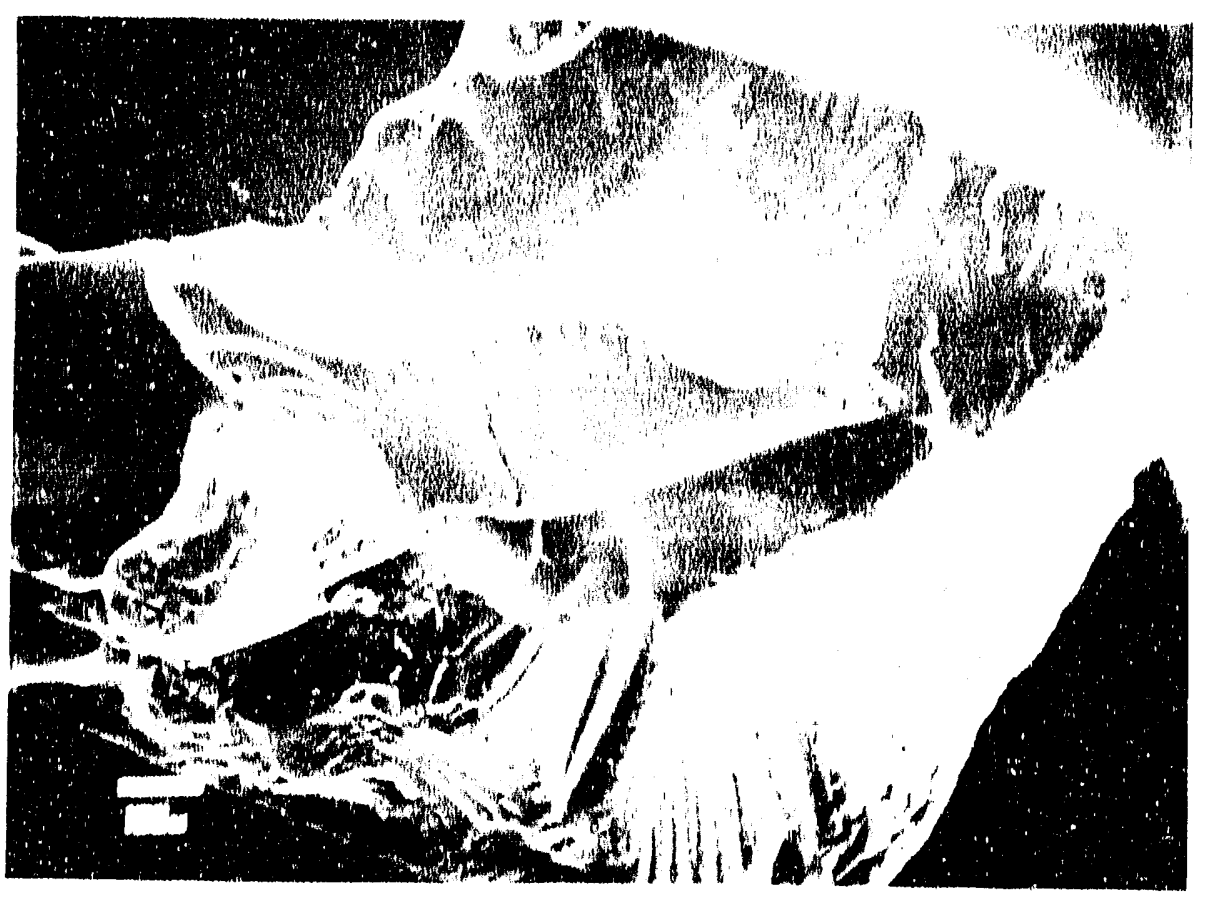

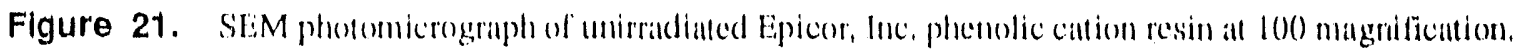




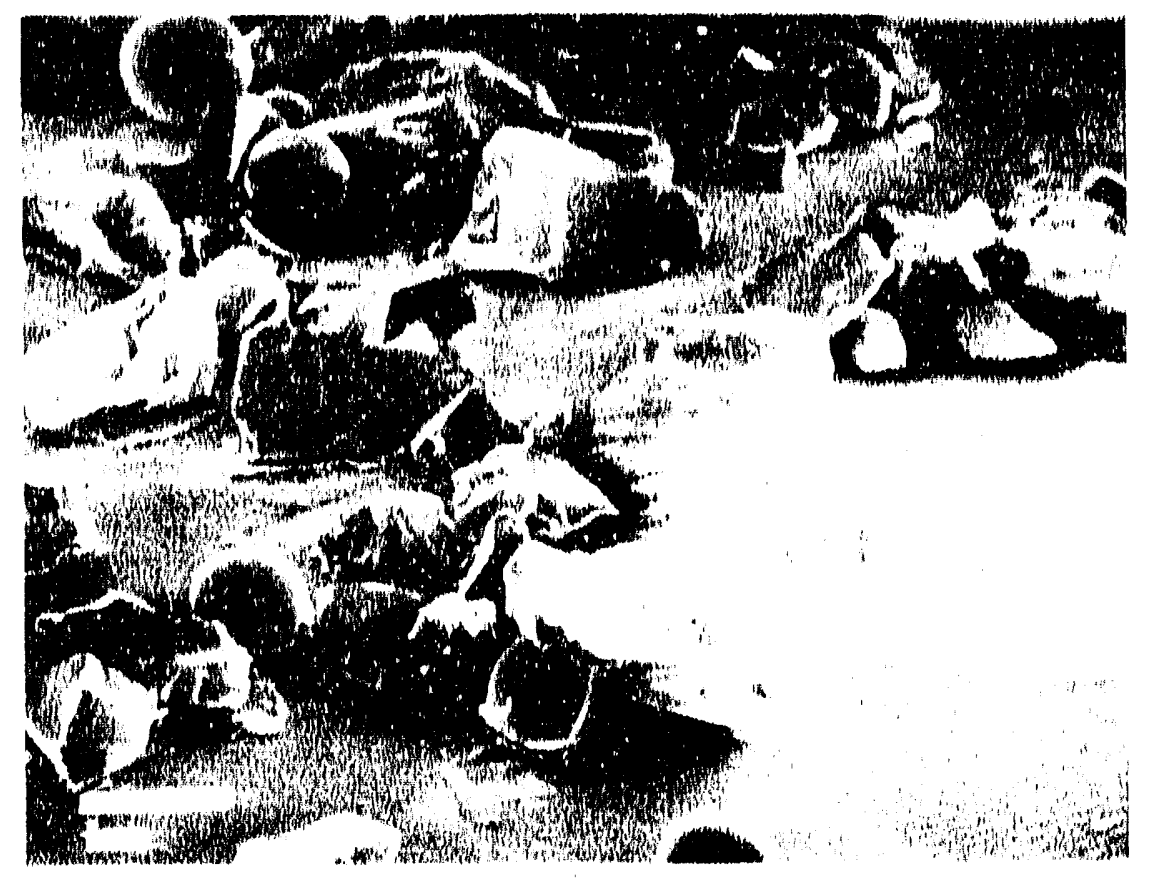

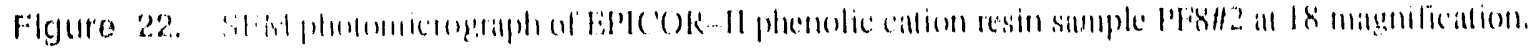

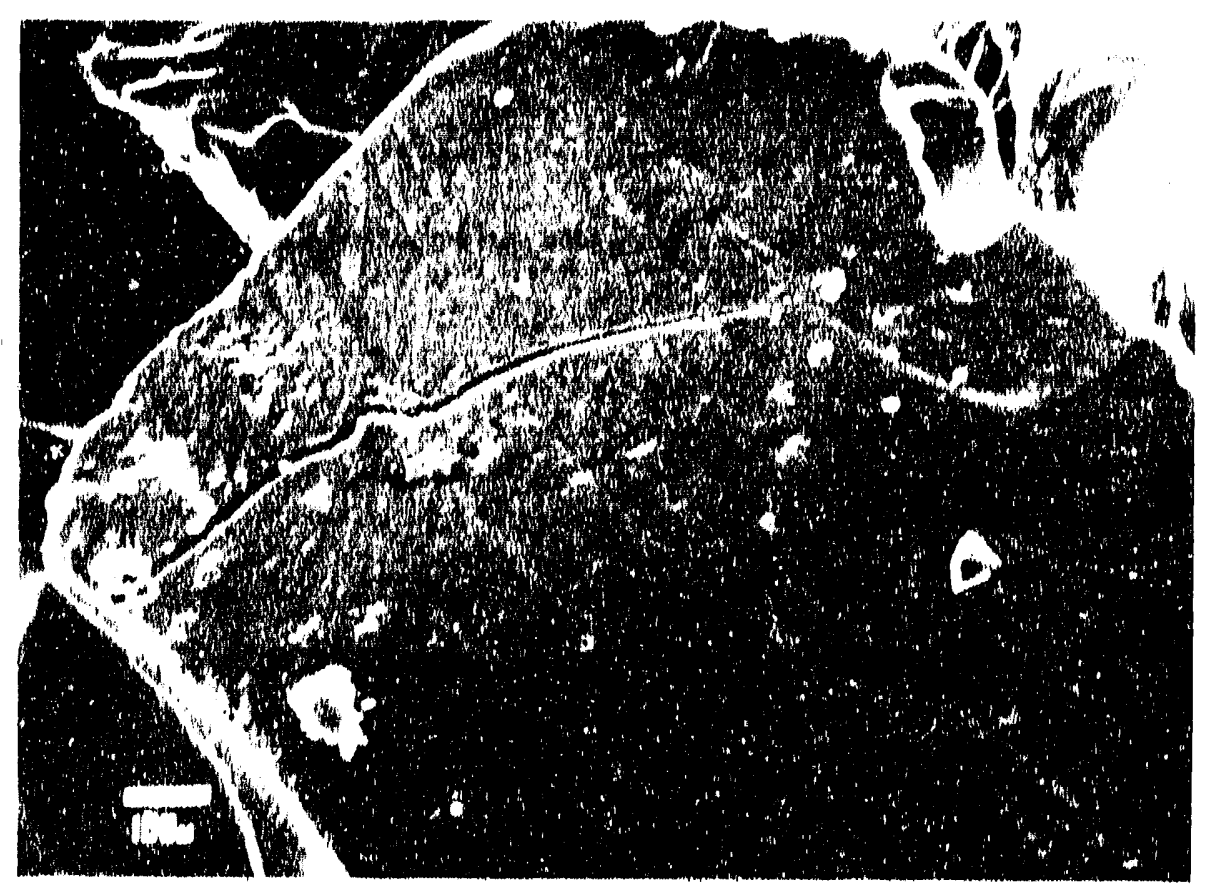

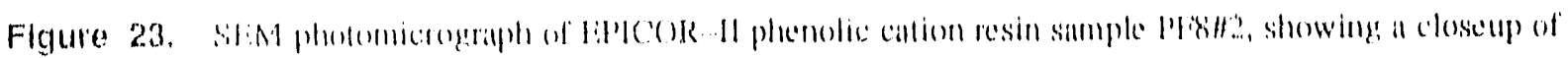

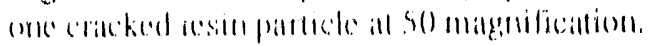




\section{Gamma--Ray Spectroscopy}

During tho third sampling, gamma-ray speotroscopy was used to deterinino the amount of radionuclides prosont in varlous aqueous samples. Significant amounts of $\mathrm{Cs}-134$ and $\left.\mathrm{Cs}-13^{\prime}\right)$ wore detected in the souk, rinso, and decant rinse solutions, Thable 6 presents the amount of Cs-134, and -137 that were found in delonized wator solutions, as woll as the total Cesium loading for tho resin samples.

\section{Physical Obsorvations}

Physical observations during the third sampling wore similar to those of the first and second sumplings with more advanced signs of degradation in evidence. The styreno base resins (PF-8\#1, PF-8\#3, and PF-20) all showed signs of stickiness and ngglomeration more severe than tho socond sampling. Coring of the prefiltors was more diffloult than oithor provlous coring with resins offering more resistance to the coring tool, Vacuum removal of samples from the cores was impeded by plugging of the vacuum entrance of the tube by resins (a now experience). Only by repeated rinsing of the wand with demineralized water was it possible to continue the process. With the resin samples in columns, flow could not bo inittated for the first rinso (vacuum assist was no holp), Tho samples woro each washed into a beakor and rinsed to remove a vis. ible sediment. Tho sediment was decanted off and the resins wore then returned to the columns for olution. The olution process was thon performed as planned. PF-8\#1 and PF-8\#3 both appeared dark orange to brown in color. The 7-ycar-old unitradiated rosin was still a light amber color, PF-20 resin sumples also had a significant ohango in color (mosily orange).

During coring operations, water was I lded to the top of ench profiltor bed to ald in corling $t(x)$ insertion. 'That water ran across the bed to onter previlous coro holes rather than soak directly into tho bed as would normally occur. Provious experience with EPICOR prefilters whioh had lower radiation doses showod that water would normally flow direcily into the bed.

\section{Synopsis of Results}

Table 7 presents results of the various analytical tosts performed on the irradiated EPICOR -..II resin samples. It should be noted that results in the table are expressed in torms of differences in values obtained from tests on the irmadiated EPICOR-II rusins from the first, second, and third samplings versus the values obtalned from tests on the unirradiated Epleor, Inc. supplied resins.

Table 6. Ceslum measured in aqueous solutions from resins-third sampling

\begin{abstract}
All Aqucous Solutions From Resin Sample No.
\end{abstract}

PF-8\#1

PF-8\#2

PFI-8\#3

PF-20
Total mCi/100 mL Resin Sample

\begin{tabular}{rrr} 
Cs-134 & Cs 137 & Total Cs \\
\cline { 2 - 3 } 650 & 74,089 & 74,139 \\
95 & 11,183 & 11,278 \\
1141 & 130,242 & 131,383 \\
930 & 108,215 & 109,145
\end{tabular}




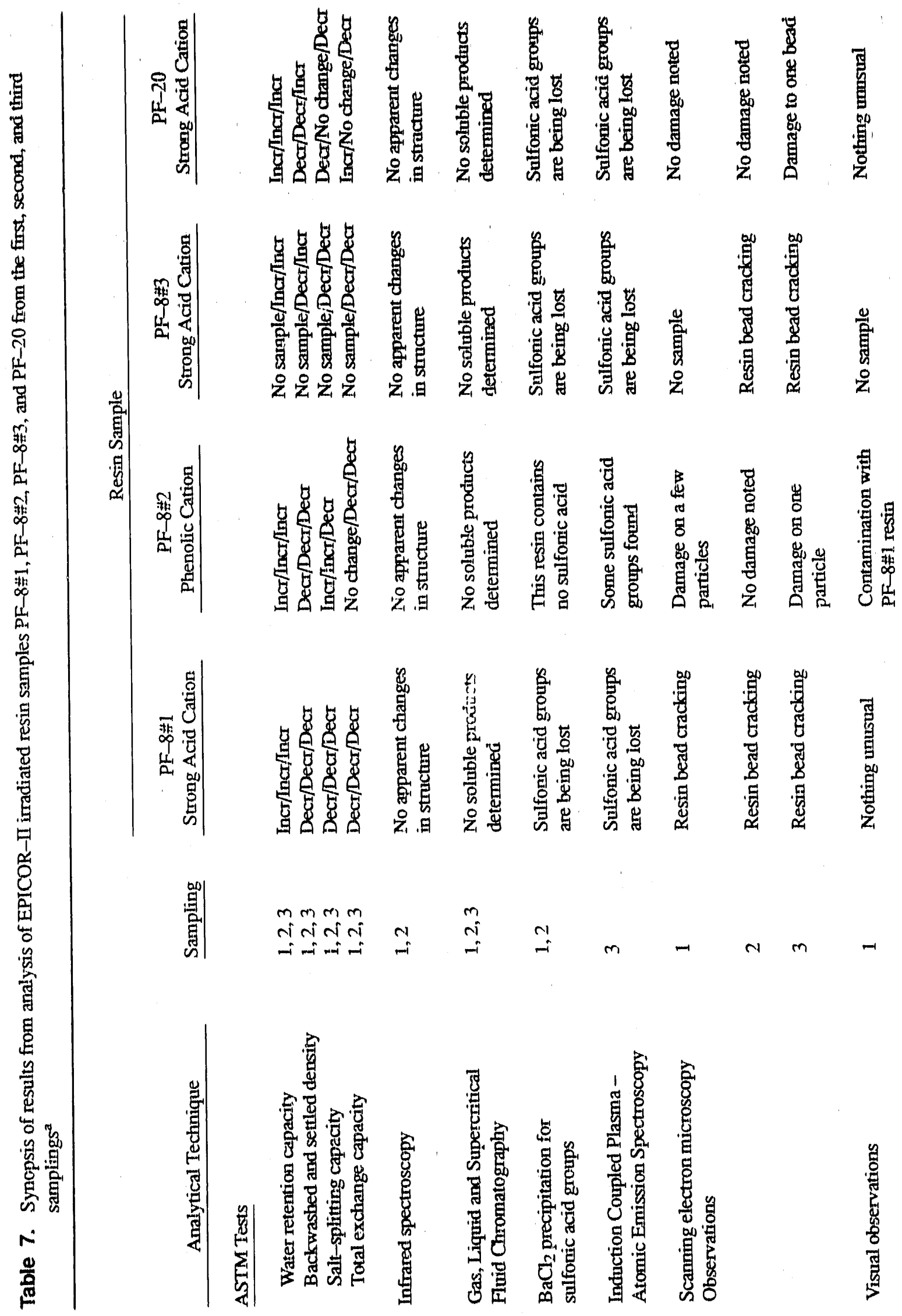




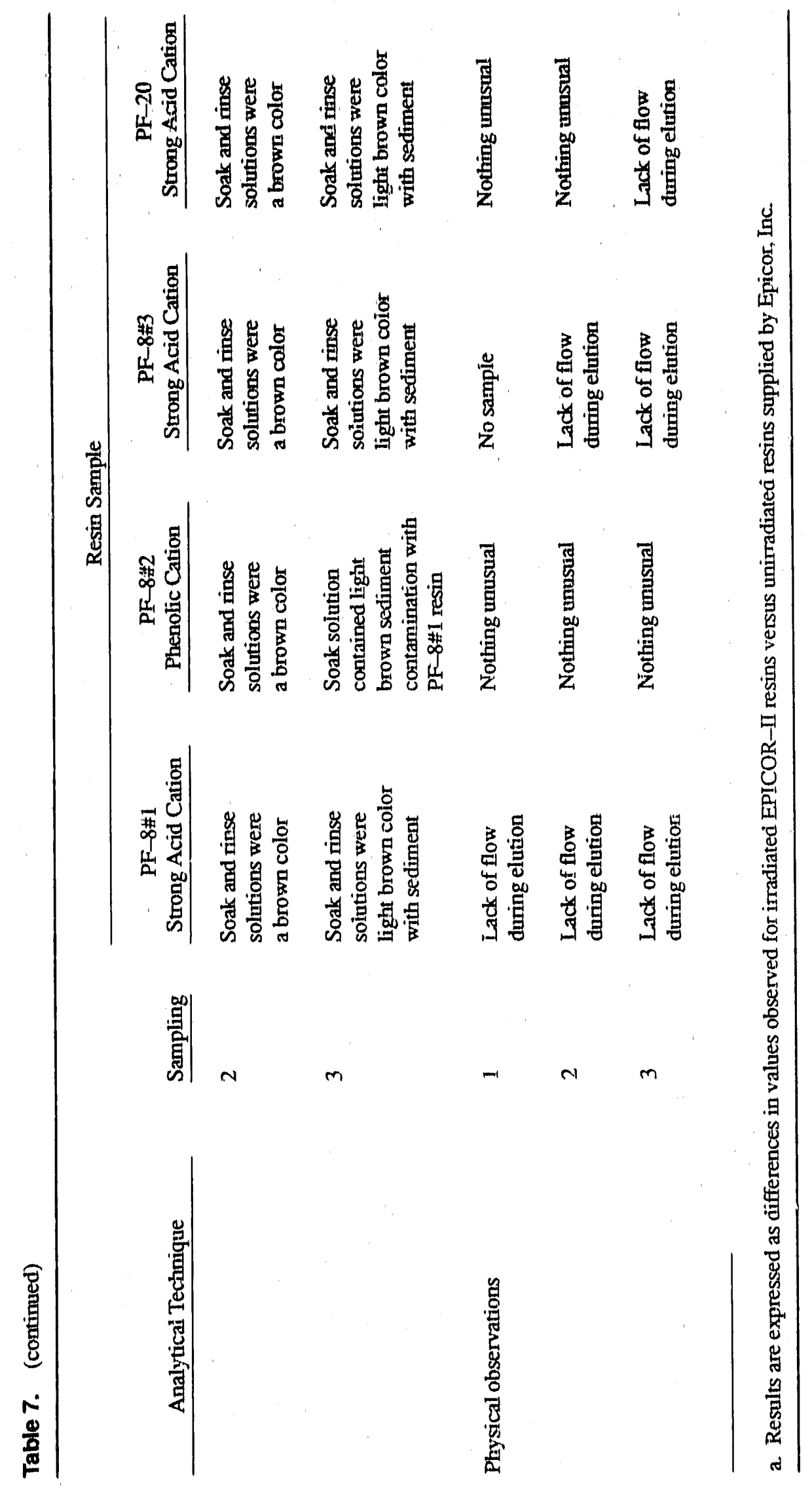




\section{DISCUSSION AND CONCLUSIONS}

Severul important studies of ton exchange resins have been conducted, including research by Battelle Columbus Laboratory (BCL $)^{13,14}$ Brookhaven National Laboratory (BNL), 7,12,19,16 and the Idaho National Engineoring Laboratory (INEL) (References 3 and 4). The BCL work covered characterization of EPICOR-11 prefilters PF-3 and -16 ; the BNL research included radiation effects on fon exchange resins. A more complete discussion of the findings of those rescurchers is presentod in Reference 3 and a dis. cussion comparing $\mathrm{BCL}$ and $\mathrm{BNL}$ results with those obtained at INEL is given below. This section also compares the results from the first and second sampling of EPICOR resins $\mathrm{PF}-8$ and -20 with the results of the third sampling.

The results obtained by BNL and BCL agree with the findings of the INEL research of EPICOR-II prefilters. The following items were found during the BNL and BCL research which specifically relate to the INEL. work:

- Most cution resins show significant degriadation only after they have recelved a radiation dose greater than $10^{8}$ rad.

- The primary effects of radiation on ton exchange resins are degradation by loss of effective cross-linking of the macro. molecular structure, along with scission of ion exchange functional groups.

- The exchange capacity of ion exchange resins, in general, decreases with tncreasing radiation dose.

- In cation ion exchangers, initially there is an increase in functional groups capable of exchange, as a result of radiation in the presence of air or moisture, Those are phenolic and carboxyl groups produced as a result of oxidation.

- The initial increase in exchange sites tends to increase the total exchange capacity (TEC) of the resin. However, the accompanying scission of existing exchange groups often result in a net decrease in TEC values.

- In general, the salt forms of ion exchange resins are more resistiunt to radiation than the $\mathrm{H}^{+}$or $\mathrm{OH}^{-}$forms.
- Prolonged exposure of ton exchunge resins to radiation inflowing (dynamic) systems causes more drastic chunges in their physical and chemical properties than fon exchange resins irradiated in a static system.

- Radiation-caused chemical changes in ton exchange resins are a direct function of the total radiation dose absorbed by the resin.

INEL findings correlate with findings of other researchers; $2,7,12,15,16,17$ however, degradation has been identified in the EPICOR-II resins at a lower total integrated radiation dose than observed previously $\left(6 \times 10^{7}\right.$ versus $10^{8} \mathrm{rad}$ ) (References 2,3 , and 4).

The first and second samplings confirm that degradation in the PF-8 and -20 strong acid cation resins has occurred. The onset of degradation has also been confirmed in the phenolic cation resins of PF-8. The INEL study has shown that degradation is occurring at a lower total dose than was reported in earlier studies, 2,7,12 The physical observations noted during the third sampling of the cores are comparable with those observed during the first and second samplings (i.e., lack of flow during initial elution of the strong acid cation resins). By the time of the third sumpling, no flow through the columns of resin was obtainable by normal gravity means, and the resins had to be rinsed in a beaker to remove the visible sediment on the top of the column. The sediment was decanted off and the resins were returned to their ion exchange columns for elution. That process was successfully completed on each resin sample.

The soak and rinse solutions from the initial elution of the second and third sampling had a brown discoloration (indicating resin degradation), These are the same effects observed in resins of similar types when exposed to light for prolonged periods of time (particularly ultra violet light). The sume solutions during the first sampling were colorless. It has been found (Reference 17) that the color of the soak solution from irradiated resins changes from pale yellow to deep amber as the radiation dose increases. That change is consistent with the analytical results from the first, second, and third sampling. Also, the first, socond, and third samplings showed a pH of less than 3.0.

It is concluded from analysis of the first, second, and third samplings that the following mechanisms of degradation are occurring within the EPICOR-II strong acid cation rensins: 
- Loss of effective cross-linking (which could lead to eventual release of radionuclides if degradation progressed to the total failure of the polymer structure), as shown by the incresse in water retention capacity, decrease in sali-splitting capacity, and decrease in backwashed and settled density.

- Loss of functional groups (with accompanying loss of radionuclides), as indicated by the increase in sulfate concentrations in the various soak, rinse and elution solutions and loss in salt-spliturug capacity.

- Resins from PF-20 showed an initial increase in TEC during the first sampling due to oxidation of the polymer chain before onset of degradation (Reference 3 ). The TEC then decreased to no change in the second sampling (Reference 4). This could be caused by loss of effective cross-linking. By the third sampling, a substantial decrease in the TEC was observed, indicating that the radiation dose had exceeded the necessary dose for extensive degradation.

- All of the resins sampled are losing capacity to hold cesium, the major radionuclide found in the resin samples, as evidenced by the amount of cesium found in the soak and rinse solutions.

It is also concluded from analysis of the first, second, and third samplings that the following mechanisms of degradation are occurring within the EPICOR-II phenolic cation resins:

- Loss of effective cross-..linking (which has led to the loss of radionuclides), this was expected due the increase in the water retention capacity and the decrease in the backwashed and settled density. During the third sampling, the backwashed and settled density increased somewhat.

- Oxidation of the polymer chain (which would reduce the tendency to release radionuclides), caused an increase in the salt-splitting capacity in the first and second sampling. By the time of the third sampling, degradation had occurred to the point where substantial decresse in salt splitting capacity and total cochange capacity was observed.
Previous resin studies show that degradation caused by intemal radiation doses will be more severe than degradation caused by external irradiation, because of introduction of the radiation into the polymer structure (References 2, 7, 12,15 and 16). The intermal dose received by the organic ion exchange resins in EPICORII prefilters PF -8 and -20 has been sufficient to produce significant degradation. The degradation at the time of the first sampling was measurable, The equilibrium of the polymer structure has been shifted towards polymer breakdown; this is substantiated by results of the second and third analysis.

One important indicator of the capability of ion exchange media to retain radionuclides is total exchange capacity. The four samples examined in the INEL study exhibited different reactions to radiation in the first and second sampling. Samples PF- $8 \# 1$ and PF-8\#3, strong acid cation resins with the highest radiation dose, showed reduced total exchange capacity. Sample PF-8\#2, the phenolic cation with a slightly lower dose, showed a decrease in the second sampling. $\mathrm{PF}-20$, the strongest acid cation with the lowest dose, showed an increase in the first sampling, and dropped back to the capacity of the unirradiated resin in the second sampling. This indicates the onset of degradation that is consistent with findings of Reference 12 . That sample exhibited a significant drop in exchange capacity in the third sampling. The results of the INEL study indicate that the threshold dose for the onset of degradation due to internal radiation is between $5.1 \mathrm{x}$ $10^{7}$ and $6.6 \times 10^{7}$ rads. By the time of the third sampling, all of the resin samples had demonstrated substantial decrease in the total exchange capacity. This ranged from $23 \%$ for the phenolic resin to $35 \%$ in the PF-20 strong acid cation resin. The strong acid cation resins of PF-8 had a decrease in the total exchange capacity of about $43 \%$. These changes are graphically illustrated in Figure 12 where sample PF-20 initially increased in exchange capacity while other samples showed decreases as indicated by the negative percent change in the curves.

The radiation degradation was also seen as the loss of sulfonic acid groups in PF-8\#1, PF-8\#3, and PF-20 resin samples. The loss of sulfonic acid groups would lower the $\mathrm{pH}$ of the liquid in the surrounding ion exchange material as observed in previous samples and the third sampling (Table 6). The low-pH liquid should be neutralized by the remaining unused ion exchange material in the prefilters. That thesis is supported by the measurement of residual water $\mathrm{pH}$ from the 50 prefilters which were stored at the INEL. Fontysix of those prefilters have been disposed at the commercial disposal facility near Hanford, Washington, and four have been disposed in the Radioactive Waste 
Management Complex at the INEL. The pH measurements of residual water obtained more than three years after the prefilters were used were in the range of about 5 to 8 as compared to less than 3 for soak and rinse solutions from resin samples. Those $\mathrm{pH}$ readings indicate that the acidic solution was being modified as it passed through the cation and mixed bed resins in the lower regions of the prefilters.

A thieshold dose for degradation in EPICOR-II ion exchange resins has been identified by this work to be below $6 \times 10^{7}$ rads. That value is somewhat less than in the $10^{8}-\mathrm{rad}$ accumulated dose limit recommended in the Technical Position on Waste Form. ${ }^{18}$ The resin properties, which have changed due to degradation, such as those examined by the ASTM methods, exhibit small changes (10\% or less, as seen in Tables 3 and 4 ) at the threshold dose; while higher doses $\left(10^{8} \mathrm{rad}\right.$ and above) have produced more pronounced property changes. ${ }^{2,15,16}$ It can also be seen from the information in Tables 3 and 4 that different resins react differently at a similar dose (comparing styrene to phenolic base resin).

The results produced in this study show that EPICOR resins definitely began losing radionuclides below $10^{8}$ rads total radiation dose. But the release of a nuclide by an exchange site does not ensure that the nuclide will be released by the exchanger to the environment. The nuclide could be picked up on another site or held by the agglomerated resins. The first would be a temporary condition until a higher dose is reached, but does delay the ultimate release of the nuclide. The second would be more permanent and would not easily release the nuclide. Such processes are probably occurring within the EPICOR-II prefilters. The ion exchange process is made possible by the fact that ion exchangers are operated below the point where a predetermined level of radionuclides begins appearing in the effluent (exchanger breakthrough). That process results in a number of free sites in the exchangers being available for recapture of any loose radionuclides.

Both ion exchange recapture and retention by the gelatinous agglomerated resin mass will effectively hold the released radionuclides. It was positively shown during column elution attempts in both this study and the one conducted in Reference 2, that water flow could not be initiated through the degraded ion exchange beds and thus no nuclides elution or subsequent movement could take place. In this study, only batch rinsing resulted in nuclide releases where agglomerated resins predominated. The graphs of
Figures 2 and 3 present garnma dose with bed location. These curves have remained essentially unchanged for shape and location within the prefilter over the three samplings, which indicates that the gamma-emitting radionuclides are not moving despite addition of water during coring operations.

These analyses have assisted in determining the extent to which organic ion exchangers are degraded by internal radiation under conditions representative of actual use and storage. Degradation of the resins has been related directly to total integrated radiation dose. This has aided in identifying the effects of degradation on release of radionuclides from the ion exchange media. The resin bed in the higher radiation zone is being converted to an agglomerated mass, a substance with unique new nuclide retention capabilities. It has been shown that the contained radionuclides remain within the ion exchange bed. The acceptability of EPICOR-II prefilters for disposal in high integrity containers at a commercial disposal site is thus confirmed.

No further examinations were planned for $\mathrm{PF}-8$ and -20 resins and all sample materials and those prefilters have been disposed. However, the authors recommend that certain other studies of ion exchange resins be undertaken to examine aspects of resins degradation not included in the work discussed in this report. This study was restricted to only two types of strong acid cation resins, those with styrene and phenolic structures. Studies should be performed on degradation of newer acrylic and styrene structured resins, both cation and anion, now used in nuclear power stations with internally and externally irradiated samples having various radiation doses applied to samples of each resin type. The conduct of tests within the proper test matrix would provide data for determining thresholds of degradation for those resins. Laboratory scale leaching of those irradiated resins could be used to further identify the part that bed agglomeration plays in retaining radionuclides. Resins would be loaded with such commonly encountered radionuclides as $\mathrm{Cs}-137$ and Co-60 to facilitate the study of nuclide retention.

An important aspect of irradiation degradation of resins is gas generation, which occurs during that irradiation. In particular the generation of hydrocarbons from the degradation of resins is information that can be used in planning for and regulating the disposal of long-term storage of ion exchange resins. The studies of resin degradation could also incorporate measurement of gas generation caused by irradiation. 


\section{REFERENCES}

1. J. W. McConnell, Jr., EPICOR-II Resin/Liner Research Plan, EGG-TMI-6198, March 1983.

2. K. K. S. Pillay, Radiation Effects on Ion Exchangers Used in Radioactive Waste Mamagement, NE/ RWM-80-3, Pennsylvania State University, October 1980.

3. J. W. McConnell, Jr., and R. D. Sanders, Sr., EPICOR-II Resin Degradation Results from First Resin Samples of $P F-8$ and $P F-20$, NUREG/CR-4150, EGG-2176, May 1985.

4. R. D. Sanders, Sr, and J. W. McCo: nell, Sr, EPICOR-II Resin Degradation Results from Second Sampling of $P F-8$ and $P F-20$, NUREG/CR-4608, EGG-2452, October 1986.

5. Program Plan of the EPICOR and Waste and Disposition Program, EGG-TM1-6521, Revised December 1983.

6. J. W. McConnell, Jr., R. S. Lynch, and M. J. Tyacke, Commercial Disposul of High Integrity Comainc's (IIICs) Containing EPICOR-II Prefilters from Three Mile Island, GEND-048, September 1985.

7. K. J. Swyler, C. J. Dodge, R. Dayal, Irradiation Effects on the Storage and Disposal of Rudwraste Containing Organic lon-Exchange Media, NUREG/CR-3383, BNL-NUREG-51691, October 1983.

8. J. D. Doyle, J. W. McConnell, Jr., R. D. Sanders, Sr., EPICOR-II Resin Characterization and Proposed Methods for Degradation Analysis, EGG-TMI-6489, Rev. 1, June 1984.

9. H. W. Reno, J. W. McConnell, Jr., R. C. Schmitt, EPICOR-Il Research and Disposition Program: FY-1983 Anmual Report, EGG-2287, April 1984.

10. L. D. Koeppen and J. W. Rogers, TMI EPICOR-II Resin Core Samples PF-8 and PF-20, RE-PB--()48-83, EG\&G Idaho, Inc, November 1983.

11. ASTM D2187-77, Standard Test Methods for Physical and Chemical Properties of Particulate IonExchange Resins, 31.

12. 'T. E. Gangwer, M. Goldstein, and K. K. S. Pillay, Radiation Effects on Ion Exchange' Material, BNLm-50781, April 1978.

13. N. L. Wynhoff and V. Pasupathi, Characterization of EPICOR-II Prefilter Liner 3, GEND-027. April 1982.

14. J. D. Yesso, V. Pasupathi, L. Lowery, Characterization of EPICOR-II Prefilter Line'r 16, GEND-015, August 1983.

15. T. E. Gangwer and K. K. S. Pillay, Radioactive Loading of Ion Exchange Materials: Radiation Reluted Areas of Concern, BNL-NUREG-28647, October 1980.

16. R. E. Barletta, K. J. Swyler, S. F. Chan, R. E. Davis, Solidification of Irradiated EPICOR-II Waste Products, NUREG/CR 2969, BNL-NUREG-51590, May 1983.

17. K. Swyler, R. E. Barletta, R. E. Davis, Review' of Recent Studies of the Radiation Induced Behavior of Ion Exchange Media, BNL-NUREG-28682, November 1980.

18. United States Nuclear Regulatory Commission, Technical Position on Waste Form, May 11, 1983. 


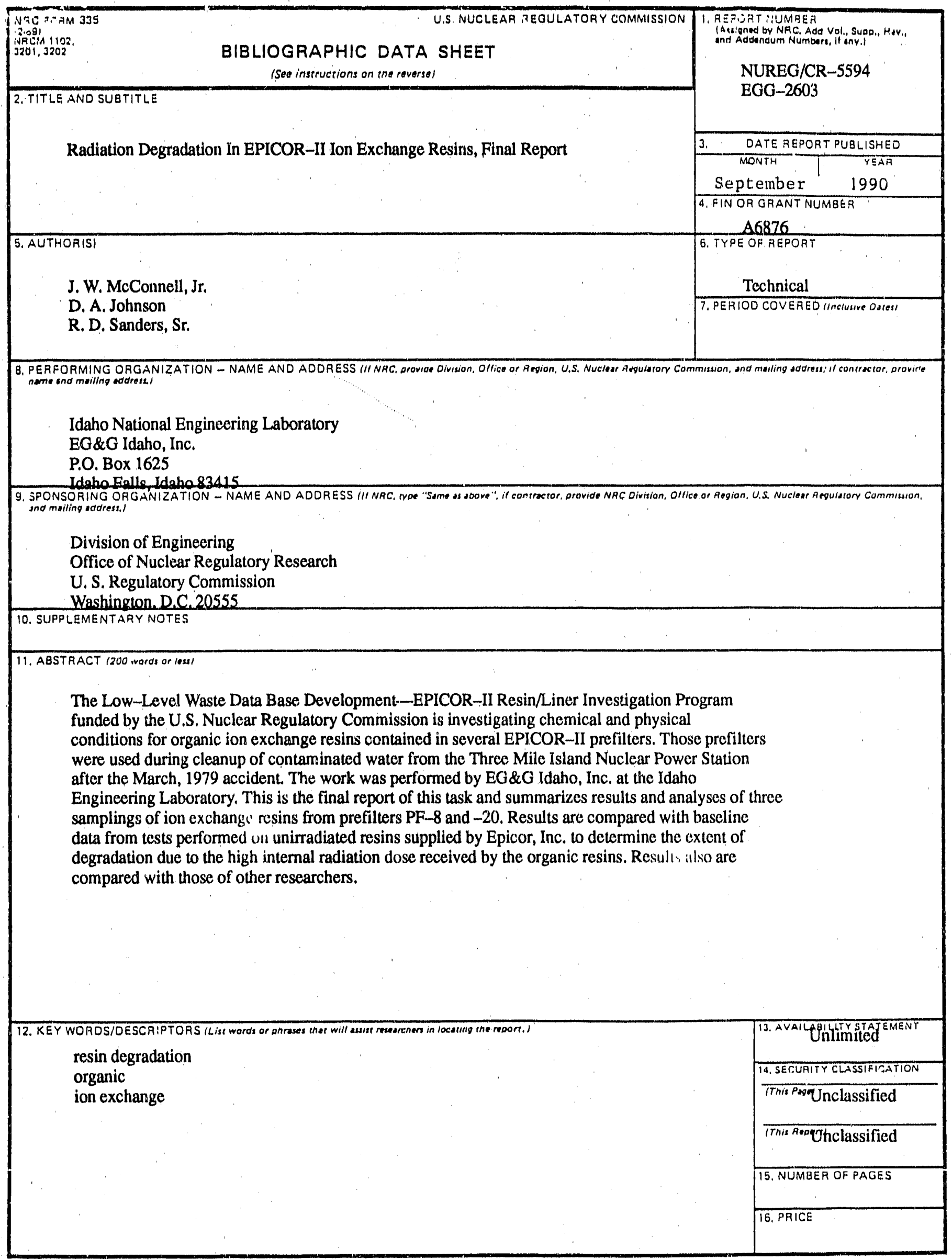



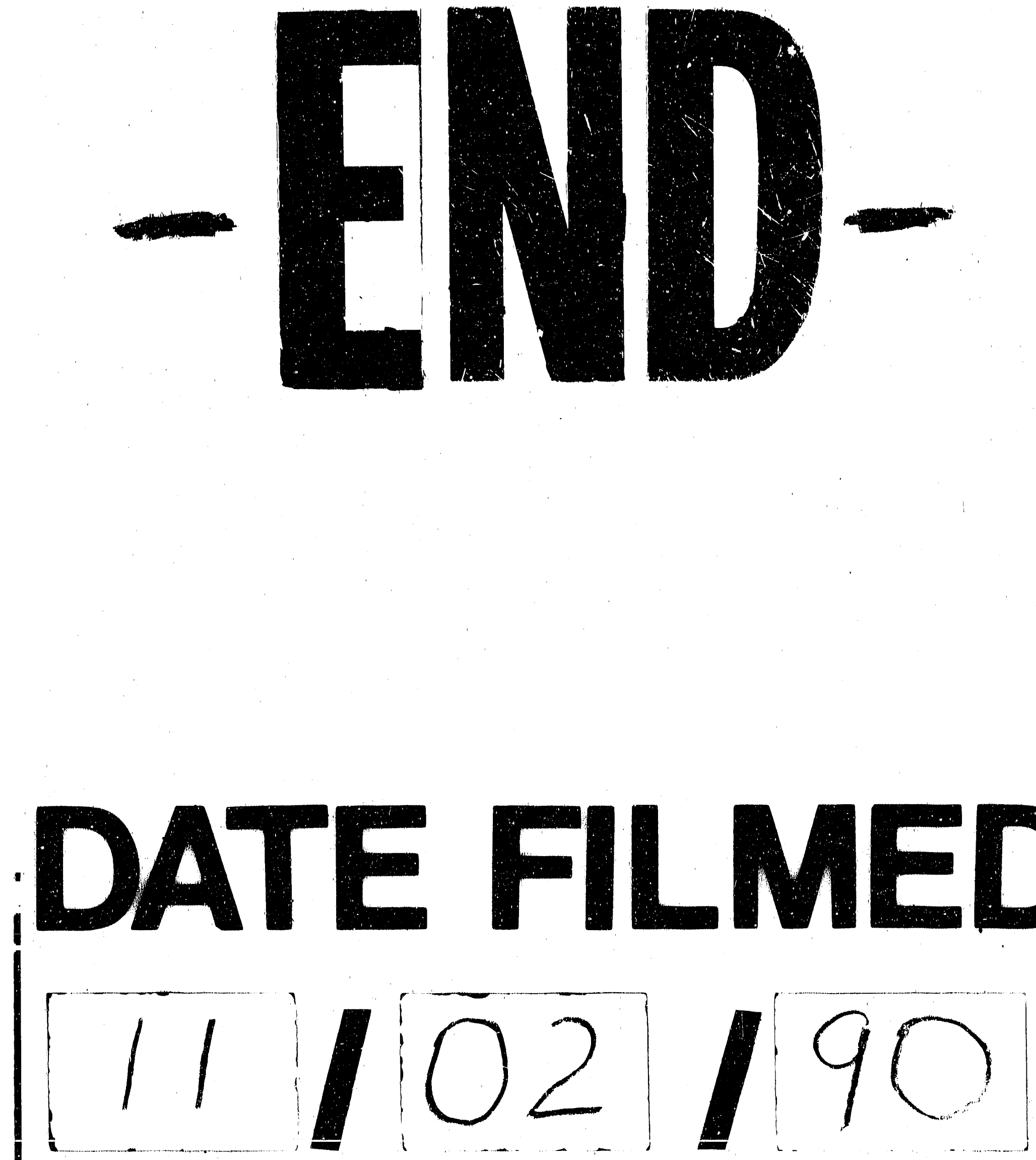
